\title{
Smart gating porous particles as new carriers for drug delivery
}

Kamonchanok Thananukul ${ }^{1,2}$, Chariya Kaewsaneha ${ }^{2}$, Pakorn Opaprakasit ${ }^{2}$, Noureddine Lebaz ${ }^{3}$, Abdelhamid Errachid ${ }^{1}$, Abdelhamid Elaissari ${ }^{1 *}$

${ }^{1}$ Univ Lyon, University Claude Bernard Lyon-1, CNRS, ISA-UMR 5280, 69622 Villeurbanne, France

${ }^{2}$ School of Bio-Chemical Engineering and Technology, Sirindhorn International Institute of Technology (SIIT), Thammasat University, Pathum Thani 12121, Thailand

${ }^{3}$ Univ Lyon, University Claude Bernard Lyon-1, CNRS, LAGEPP-UMR 5007, CPE, 43 bd 11 Novembre 1918, F69622 Villeurbanne, France

*Corresponding author: abdelhamid.elasissari@univ-lyon1.fr

\begin{abstract}
The design of smart drug delivery carriers has recently attracted great attention in the biomedical field. These smart carriers respond to physical and chemical changes in their environment, including changes in $\mathrm{pH}$, temperature, light, and specific agents. The porous structure of the particles plays an important role in facilitating the diffusion of drug molecules and cell attachment. Smart gatekeepers provide advanced functions such as "open-close" switching by grafting stimuliresponsive polymers onto the particle's pores. These controlled delivery systems enable drugs to be targeted at specific rates/time-programmes and sites of the human body. This review proposes the integration of porous particles and stimuli-responsive gatekeepers for effective drug delivery. The fabrication techniques of porous materials, gate structures, triggered targeting strategies, and controlled release mechanisms are detailed. Current ongoing research and future trends in drug delivery applications are highlighted.
\end{abstract}

Keywords Stimuli-responsive polymers; Drug delivery; Biomedicine; Gatekeeper; Porous particles

\section{Graphical abstract}

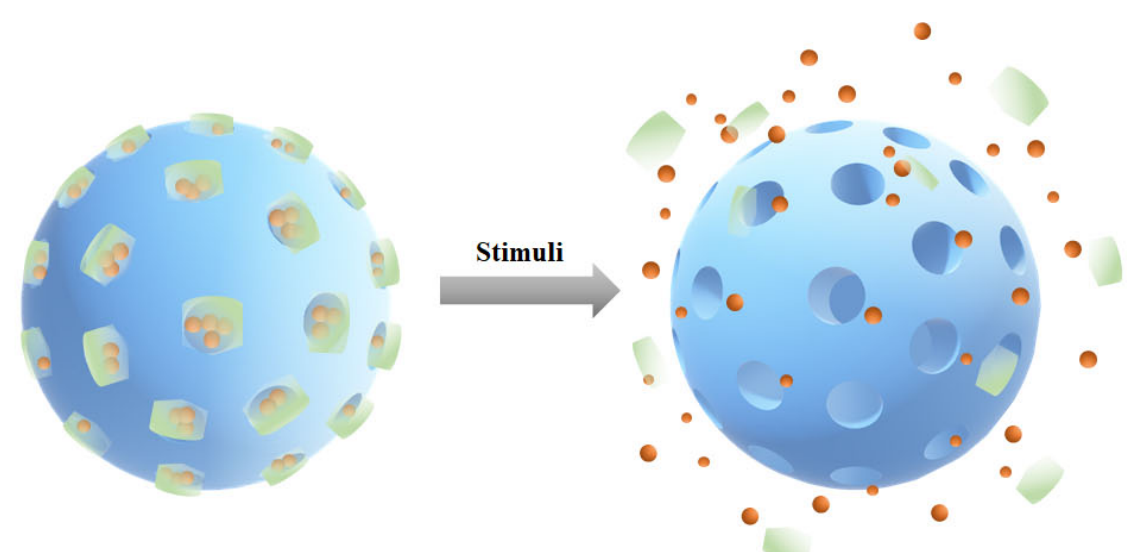

Porous particles

- Active molecules

Stimuli-responsive gatekeepers 


\section{Introduction}

Stimuli-responsive polymers have attracted growing interest over the last few decades for a diverse range of applications, e.g., drug delivery, gene delivery, sensors, and tissue engineering [1-3]. Inspired by natural living cells, stimuli-responsiveness is a crucial function for maintaining human body balance and self-healing. These polymeric "smart materials" correspond to biological environment stimuli such as $\mathrm{pH}$ [4], temperature [5], electric and magnetic fields [6], ion concentration [7], light [8], chemical, and biological stimulus [9]. Stimuli act as triggers that can be applied externally and remotely to achieve the controlled release of active molecules from drug carriers [10]. Sensitive materials may be swelled, collapsed, crosslinked or degraded in soluble media. This characteristic makes these smart polymers important agents for drug delivery systems, among other applications. Recent progress in the synthesis of smart polymeric carriers for drug delivery applications has been discussed, focusing on $\mathrm{pH}-$, photo- and thermo-responsive polymers [11-14].

In the preparation of stimuli-responsive polymeric carriers for drug delivery applications, an important step is not only the selection of an appropriate stimuli-responsive polymer material according to final applications sought, including sites and modes of administration, but also the selection of an encapsulation method for the entrapment of therapeutic agents. Encapsulation entraps active ingredients inside reservoirs which enable the protection of active agents against light, oxidation, and enzyme degradation, and their controlled release [15]. The drug encapsulation process usually depends on the hydrophilicity or hydrophobicity of the molecules employed [16]. Several encapsulation processes exist and they may be divided into two main groups: (i) coacervation based on chemical techniques, e.g., suspension polymerization, emulsion polymerization, miniemulsion polymerization, and interfacial polymerization, (ii) physicomechanical methods, e.g., spray drying, microfluidics and the layer-by-layer technique [17-19]. Generally, stimuli-drug carriers are synthesized using polymer matrices or other structures including nanogels, micelles, core/shell- like particles and capsules. The external stimulus provokes carrier disassembly or disintegration. When the particles swell or break down into polymer chains, they become porous, allowing drug release [20].

Conventional particles for drug delivery are usually spherical in shape with a variety of morphologies, e.g., solid particles, core/shell particles, and porous particles [21-23]. In order to control the release of active agents, solid and core/shell structures provide slow release, while 
porous structures present a high initial burst release due to high particle porosity [22]. Owing to the release behavior, porous particles are suitable for application as stimuli-responsive gatekeepers for drug delivery systems. Porous particles have been fabricated with a variety of pore sizes, densities, and morphologies. The large surface area of porous structures facilitates drug diffusion and cell attachment, with improved absorption/adsorption properties of hydrophobic or hydrophilic drugs into microcapsules [24]. Porous particles can be fabricated by both inorganic and organic materials. Mesoporous silica materials are excellent carriers for drug delivery due to the high loading efficacy of the drugs inside the pore channels and easy functionalization [25, 26]. Pore size is also an important factor for permeability; large pores generally enhance permeability [27]. Synthetic polymers have been employed in the synthesis of porous particles by many techniques, including microfluidics, seed polymerization, and double emulsion polymerization [28]. Recently, porous biodegradable materials e.g., poly(lactide) [29, 30], poly(lactic-coglycolide) [22, 31], poly(caprolactone) [32], and Eudragit ${ }^{\mathbb{R}} \mathrm{RS} 100$ [33], have been prepared [34, 35]. These biodegradable polymers show outstanding attributes of biocompatibility, high stability in blood, and degradability in the body. The degradation kinetics of polymers are dependent on functional groups, polymer structure, molecular weight, and the body's biological environments (e.g., $\mathrm{pH}$, temperature and enzymes) [36].

The main focus of this review is to highlight the utility of stimuli-responsive polymers as gatekeepers to control the drug diffusion through the porous carriers. Smart gating porous particles serves the purposes to trigger the drug delivery system by an external- or internal- stimuli and improve the surface properties of the bare particles. Functional gates can be switched to transport drug molecules from inside the particles to the surrounding environment [37]. An external stimulus immediately triggers therapeutic drug release at a target site. Current studies have focused on the development of sensitive tunable gates, prepared by surface-initiated polymerization and the layerby-layer method [38]. This review explores new trends of stimuli-responsive porous particles, fabrication techniques, the drug release mechanisms, and briefly practical use in biomedical field. This is one of the promising candidates with potential opportunities for stimuli-responsive drug delivery.

\section{Porous particles for drug delivery applications}

Porous particles are a group of drug carriers which are widely reported in drug delivery applications and tissue engineering, due to their large surface area, high porosity, uniform and 
tunable pore structures, and surface modifiability [39-41]. Porous particles are mainly prepared by using templating agents, porogens, self-forming pores and specific chemical synthesis [40].

\subsection{Preparation of porous particles}

Recently, several reviews on porous micro/nanoparticles introduced the features and synthetic techniques involved. These materials are classified based on their pore formation mechanisms, including a self-forming technique, and the use of templates or pore forming agents. In addition, specific preparation processes are also employed to produce porous particles, such as microfluidizer and spray drying techniques. The main advantages and limitations of each porous particle formation technique (i.e., synthesis of mesoporous silica nanoparticles, double emulsion solvent evaporation, templates, and pore-forming agents, microfluidics and spray drying techniques) regarding the properties and performance of drug delivery systems are summarized in Table 1.

Table 1 Advantages and limitations of pore forming techniques for drug delivery.

\begin{tabular}{|c|c|c|c|}
\hline Techniques & Advantages & Limitations & Ref. \\
\hline $\begin{array}{l}\text { Synthesis of } \\
\text { mesoporous silica } \\
\text { nanoparticles } \\
\text { (MSNs) }\end{array}$ & $\begin{array}{l}\text { 1. Large porosity and surface area. } \\
\text { 2. More stability and uniform } \\
\text { particles. } \\
\text { 3. Ease of surface modification. } \\
\text { 4. High drug loading capacity. }\end{array}$ & $\begin{array}{l}\text { 1. Possible interactions with the } \\
\text { reticuloendothelial system and } \\
\text { accumulation in the body. }\end{array}$ & [39-42] \\
\hline $\begin{array}{l}\text { Double emulsion } \\
\text { solvent evaporation }\end{array}$ & $\begin{array}{l}\text { 1. Encapsulation of both hydrophilic } \\
\text { and hydrophobic active agents in a } \\
\text { single carrier. }\end{array}$ & $\begin{array}{l}\text { 1. Two-step process. } \\
\text { 2. Polydispersity and variable pore } \\
\text { sizes. } \\
\text { 3. Instability. } \\
\text { 4. Difficult to scale up }\end{array}$ & $\begin{array}{l}{[19,43,} \\
44]\end{array}$ \\
\hline $\begin{array}{l}\text { Templates and pore } \\
\text { forming agents }\end{array}$ & $\begin{array}{l}\text { 1. Uniform pore size and structure. } \\
\text { 2. Good repeatability in same pattern. } \\
\text { 3. Easy setup and scalability. } \\
\text { 4. Various kinds of templates and } \\
\text { porogens. } \\
\text { 5. Easy to remove templates by solvent } \\
\text { or calcination. }\end{array}$ & $\begin{array}{l}\text { 1. The elimination of the template } \\
\text { may lead to the collapse of parts of } \\
\text { the pore structure. } \\
\text { 2. Leaching of pore-forming agents } \\
\text { may also remove encapsulated } \\
\text { active agents. }\end{array}$ & $\begin{array}{l}{[40,45-} \\
48]\end{array}$ \\
\hline Microfluidizer & $\begin{array}{l}\text { 1. Monodisperse particles. } \\
\text { 2. Finely controlled pore sizes. } \\
\text { 3. Good reproducibility. } \\
\text { 4. Low reagent consumption. } \\
\text { 5. Combination with UV curing during } \\
\text { continuous flow lithography. }\end{array}$ & $\begin{array}{l}\text { 1. Droplet size depends on channel } \\
\text { dimension. } \\
\text { 2. More complex operation. } \\
\text { 3. High cost of chip fabrication. }\end{array}$ & [49-52] \\
\hline Spray drying & $\begin{array}{l}\text { 1. Continuous and rapid operation. } \\
\text { 2. Wide range of raw materials. } \\
\text { 3. Precisely controllable size. } \\
\text { 4. Self-pore forming or use of } \\
\text { templates/porogens. }\end{array}$ & $\begin{array}{l}\text { 1. High cost and complex equipment. } \\
\text { 2. Excessive heat production. } \\
\text { 3. Particle shrinkage during } \\
\text { evaporation. }\end{array}$ & $\begin{array}{l}{[47,53-} \\
56]\end{array}$ \\
\hline
\end{tabular}




\subsubsection{Mesoporous silica nanoparticles (MSNs)}

A well-known group of inorganic porous particles is silica-based because of their large surface area, high porosity, stability, biocompatibility, and nontoxicity. MSNs have mesopores with a size ranging between 2 and $50 \mathrm{~nm}$. This attracts great interest from pharmaceutical research, and for drug delivery systems. In 1968, Stöber and Fink discovered how to synthesise monodisperse silica nanoparticles [57], although mesoporous silica materials were first used as drug delivery systems in 2001 [58]. Generally, MSNs are synthesized by the sol-gel method, using cationic surfactant templates, cetyltrimethylammonium bromide (CTAB) [59]. Figure 1 shows the structure of polymerized tetraethylorthosilicate (TEOS) in the presence of CTAB micelles. The MSNs type MCM-41 is performed by cooperative self-assembly between the CTAB micelles and the surface silanol groups. The surfactant is removed by either calcination or extraction, finally the nanopores are achieved $[41,60]$.

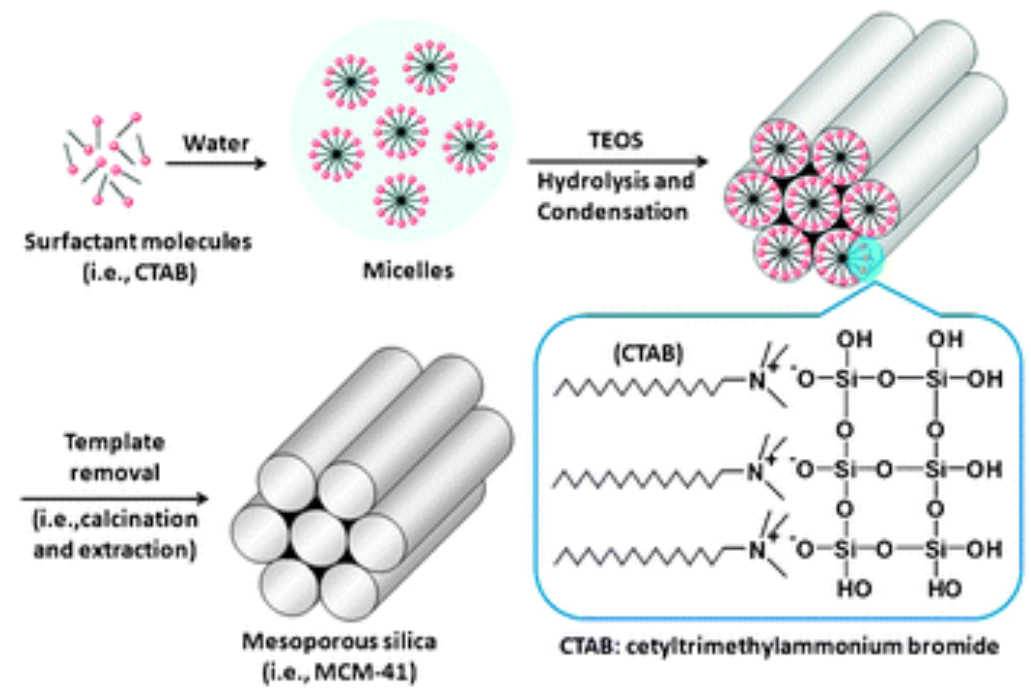

Figure 1 Schematic diagram of the formation of mesoporous silica type MCM-41. Reprinted with permission from ref. [41].

The effects of $\mathrm{pH}$, co-surfactant, basic solvent, and mixtures of alcohol/water on the pore size, morphology and uniformity of the nanoparticles have been examined [60]. The morphology of MSNs was transformed by varying synthesis parameters with the use of dual soft surfactant templates. Varying the amount of dodecanol $\left(\mathrm{C}_{12}-\mathrm{OH}\right)$ and reaction temperatures resulted in six different types of MSNs: spherically shaped, shell-like, rugby ball-like, peanut-like, hollow, and yolk-shell structures (Figure 2) [61]. In addition, chemical and physical interactions on the surface 
of MSNs can be triggered between silanol groups and functional groups present on the drug molecules, such as amino, hydroxyl, or carboxyl groups [62, 63].

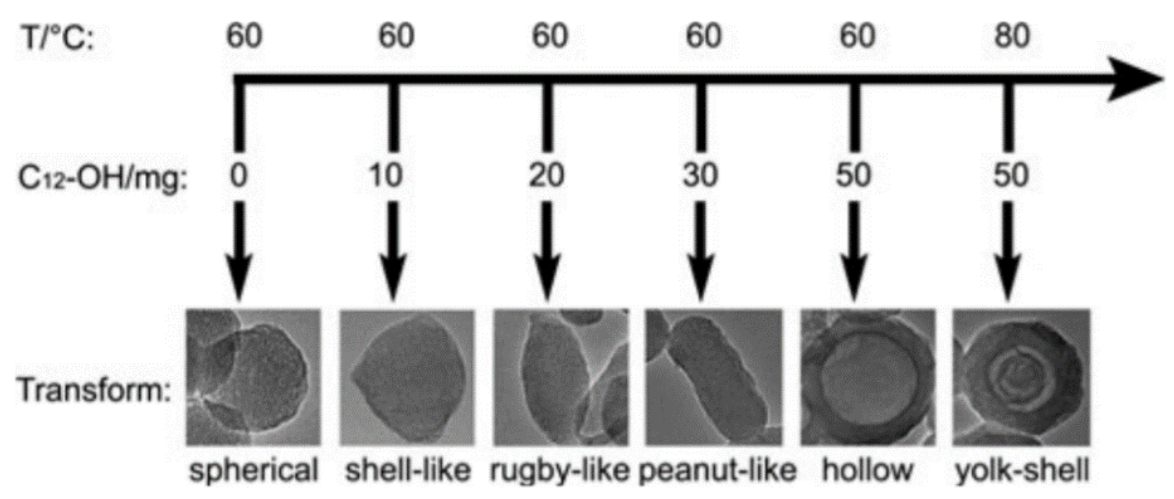

Figure 2 Schematic illustration of MSN morphologies generated by varying the amount of dodecanol and reaction temperature. Reprinted with permission from ref. [61].

\subsubsection{Double emulsion solvent evaporation technique}

The multiple step emulsion method consists of self-pore formation without porogens or templates. This method is generally combined with solvent evaporation for producing porous microspheres. Basically, the double emulsion may be a water-oil-water $(\mathrm{W} / \mathrm{O} / \mathrm{W})$ or an oil-wateroil $(\mathrm{O} / \mathrm{W} / \mathrm{O})$ technique. Figure 3 illustrates the pore-forming process via $\mathrm{W}_{1} / \mathrm{O} / \mathrm{W}_{2}$ double emulsion. The process is composed of 3 steps: (i) a water-in-oil $\left(\mathrm{W}_{1} / \mathrm{O}\right)$ emulsion formation by dispersing the inner aqueous phase $\left(\mathrm{W}_{1}\right)$ in an organic solvent $(\mathrm{O})$, (ii) the formation of a double emulsion $\left(\mathrm{W}_{1} / \mathrm{O} / \mathrm{W}_{2}\right)$ by emulsifying the primary emulsion in the aqueous continuous phase $\left(\mathrm{W}_{2}\right)$, and (iii) the evaporation of the solvent $[19,64]$. By using this technique, water soluble drugs have been encapsulated by W/O/W double emulsion. The important properties of microspheres, such as droplet size distribution and double emulsion stability, can be controlled by carefully adjusting the parameters, e.g., polymer and surfactant concentrations, phase ratios, and the mixing intensity.

Various drug-loaded microspheres derived from biodegradable polymers, including poly(lactic-co-glycolide) (PLGA), poly(lactic acid), poly(caprolactone) (PCL), and ammonio methacrylate copolymers (Eudragit RS100) have been prepared using the double emulsion technique. Iqbal et al. prepared biodegradable poly(caprolactone) (PCL) porous particles using the double emulsion solvent evaporation process with an ultrasound-assisted method; it involved a two-step emulsification process [65]. In the first step, the inner aqueous phase $\left(\mathrm{W}_{1}\right)$ was homogenized with an organic phase (PCL in dichloromethane) to obtain the primary emulsion. In 
the second step, the primary emulsion was emulsified with the outer aqueous phase $\left(\mathrm{W}_{2}\right)$ containing polyvinyl alcohol (PVA) as a stabilizer using power ultrasound, followed by solvent evaporation. This method is generally combined with solvent evaporation for producing porous microspheres. The particle size is decreased by increasing the ultrasonic exposure time and amplitude, and the outer aqueous phase volume. Additionally, the particle size is also dependent on the amount of PCL and the PVA concentration [65]. Eudragit RS100 sponge-like particles were also prepared by a similar method. The well-defined porosity of the particle can be attributed to the double emulsion solvent evaporation process, as described above. The nature of the Eudragit RS100 consists of a hydrophilicity of ammonium groups which can interact with water molecules. During the solvent evaporation and precipitation, the hydrophilic cavities are generated [66].

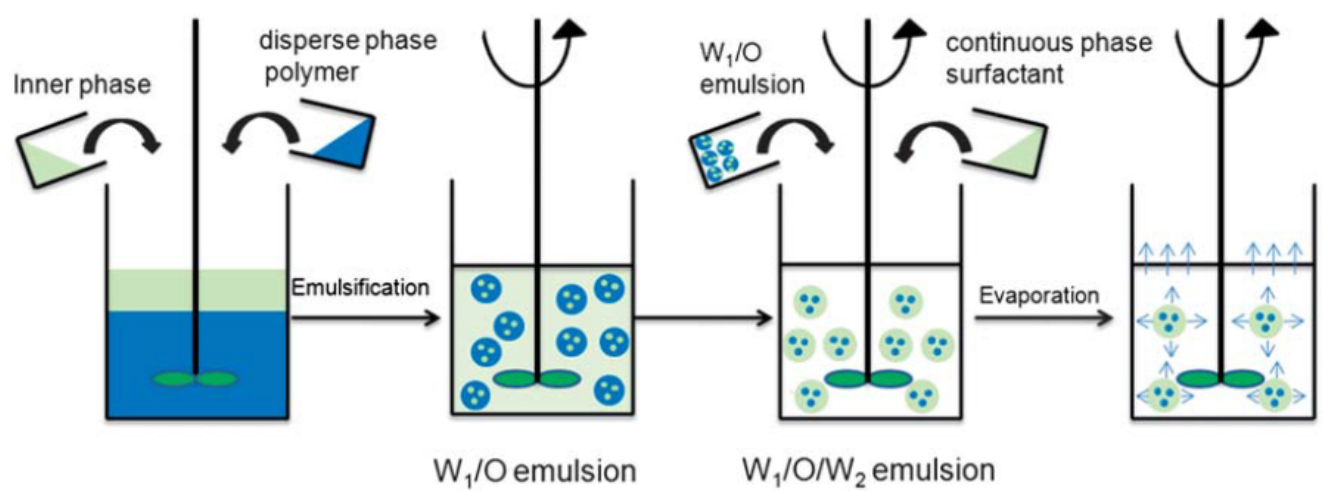

Figure 3 Double emulsion solvent evaporation method. Reprinted with permission from ref. [64].

\subsubsection{Templates and pore forming agents}

Templates or porogens are common employed for effectively controlling morphology and pore size via template removal for pore generation. Pore generation mechanisms that use templates or porogens are different, as summarized in Figure 4. Templates can be divided into two groups, depending on their physical properties, which are hard and soft templates [45, 67]. Hard templates are commonly used in the synthesis of nano/micro-structured materials, such as hollow particles, nanorods, nanowires, and nanotubes, for example polystyrene spheres [68], carbon nanospheres [69], anodic aluminum oxides, mesoporous oxides, and carbon nanotubes [70]. In the synthesis process, a polymer precursor is absorbed on the surface of the hard template, with no interaction or aggregation with the precursors in the synthesis process, due to the high stability of the hard template. The removal of the template leads to the formation of the pore structure. However, during the pore formation step, structure collapse may occur. In contrast, soft templates can self-assemble 
to form micelle-like structures, and inter- or intramolecular interactions occur (e.g., hydrogen bonding, covalent bonding, or ionic bonding) during the reaction. This creates cavity structures after the templates are removed by an appropriate solvent [45]. A precursor is deposited around the micelles or the template surfaces. The commonly-used soft templates are surfactants (CTAB for MSNs synthesis [60], and PEO-PPO-PEO (Pluronic F127) [71]) and amphiphilic block polymers (e.g., poly(styrene)-block-poly(ethylene oxide) [72], poly(styrene)-block-poly(4vinylpyridine), and poly(styrene)-block-poly(acrylic acid) [73]). The templated synthesis of porous particles typically involves the following steps: (i) preparation of the template, (ii) the synthesis of polymer particles consisting of host materials and templates (generally synthesized by colloidal methods, including emulsion polymerization, microemulsion polymerization, soap-free emulsion polymerization, suspension polymerization, dispersion polymerization, the dipping method, layer-by-layer assembly, as well as combinations with the spray drying technique), and (iii) template removal by calcination or etching [46, 47].

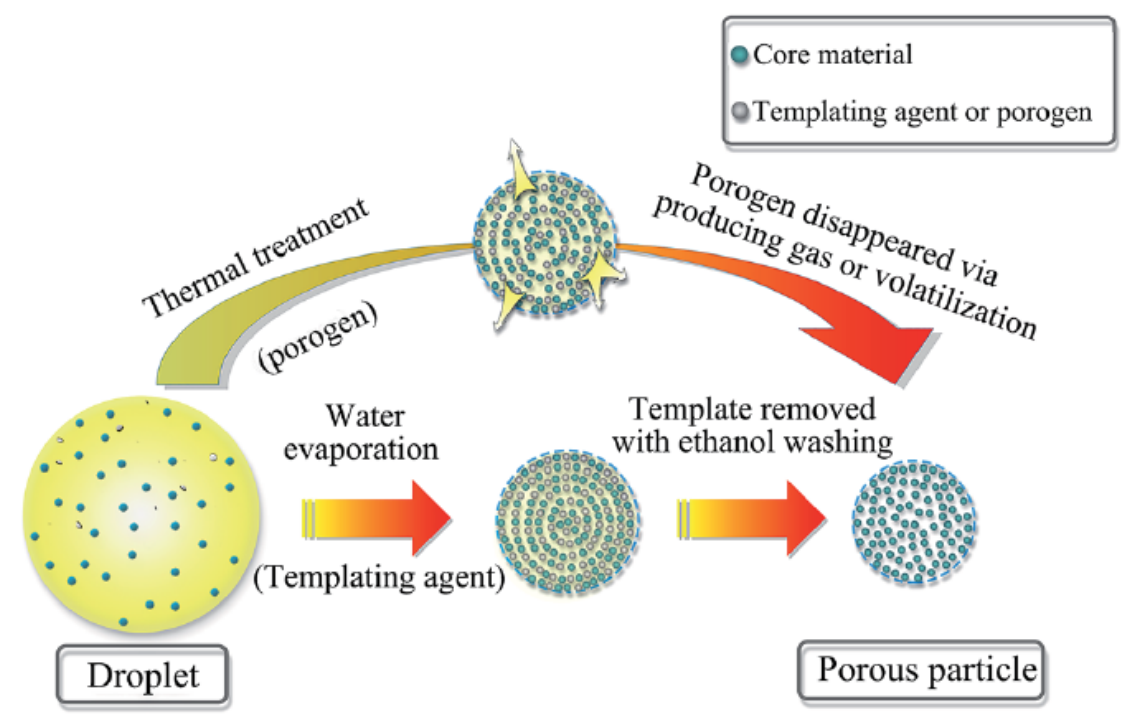

Figure 4 Schematic diagram of porous particles formation by removing templates or pore forming agents producing the cavitation. Reprinted with permission from ref. [40].

Pore-forming agents are commonly employed in the pore formation step by gas foaming or volatilization in the system. These agents are called "porogen and osmogen". Types and structures of the pore-forming agents impose strong effects on the resultant porous particle's morphology, porosity, surface area, pore volume, and mechanical stability. As porogen is inert and can be homogeneously dissoluble within an organic phase, its removal leads to both external and 
internal pores [48]. Three main requirements may be listed for porogens selection: (i) non reactivity with the precursor, (ii) solubility in the solvent, and (iii) miscibility with other substances (e.g., monomers, initiator and crosslinker) [74, 75]. Low molecular weight polymers (e.g., polyethyleneglycol, PEG) or surfactants are usually used as porogens. Nevertheless, few articles have reported the use of carbon dioxide gas as a porogenic agent. However, the fabrication of porous particles can be achieved by using ammonium bicarbonate $\left(\mathrm{NH}_{4} \mathrm{HCO}_{3}\right)$ as porogen, which spontaneously produces $\mathrm{CO}_{2}$ and $\mathrm{NH}_{3}$ to generate pores [76]. Another type of pore-forming agent is osmogene, a water-soluble component whose osmotic pressure acts as a driving force to produce tiny pores. Osmotic agents can generally generate osmotic pressures ranging from 8 to $500 \mathrm{~atm}$ [77]. The presence of high osmotic pressure as a result from inorganic salts or carbohydrate compounds (e.g., fructose, sucrose, and dextrose) is used to fabricate porous materials for use in oral controlled delivery [78]. Pore-forming agents are classified by their pore-generation mechanisms: salt leaching, gas foaming, and phase separation, by either porogen or osmogen, as shown in Figure 5. The types and amounts of pore-forming agent are important factors in controlling pore structures and sizes. A large amount of pore-forming agent produces large pore granules, while its type affects pore formation mechanisms [74, 79]. Table 2 lists the examples of using pore forming agents in the preparation of porous microspheres.
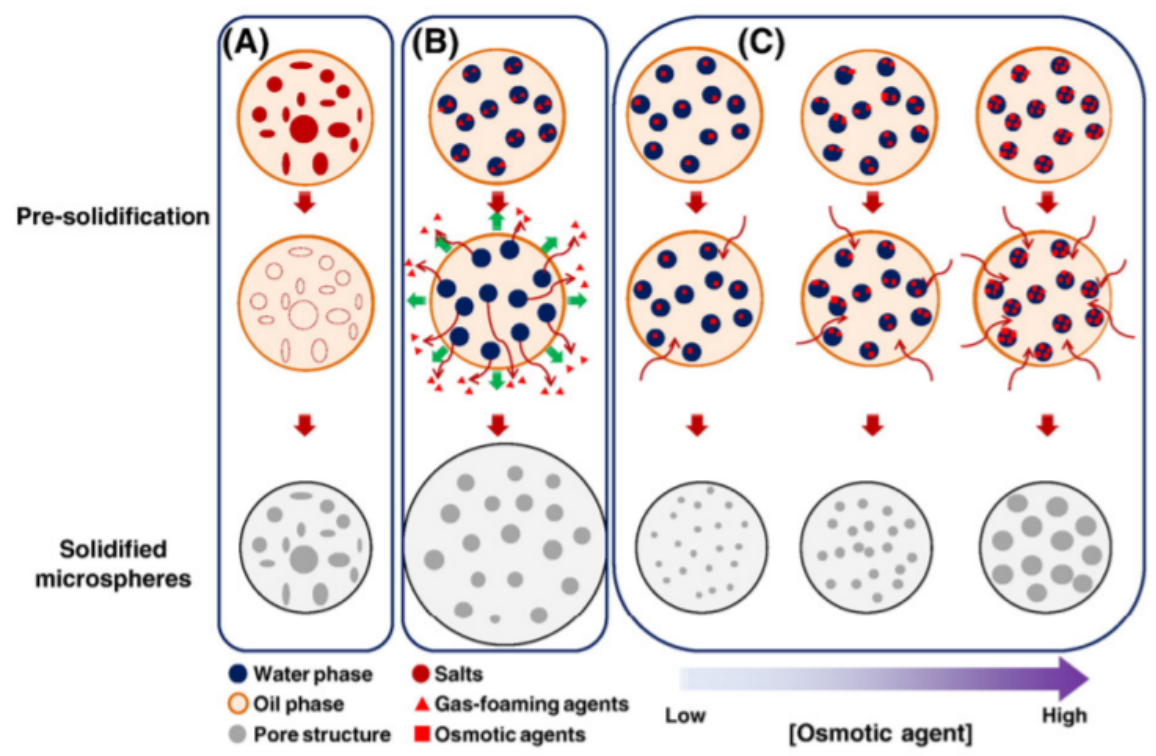

Figure 5 Schematic illustration of porous particle preparation by using different types of poreforming agents: (a) salt leaching, (b) gas foaming, and (c) osmogen. Reprinted with permission from ref. [79]. 
Table 2 Examples of pore-forming agents, polymeric shells, encapsulated active ingredients, and methodologies.

\begin{tabular}{|c|c|c|c|c|c|}
\hline Types & Pore forming agents & Polymer & Methodology & Active ingredient & Ref. \\
\hline \multirow[t]{11}{*}{ Porogen } & Dibutylphthalate & PMMA & Seed swelling polymerization & - & [80] \\
\hline & PEG-PPG-PEG & PMMA & $\mathrm{O} / \mathrm{W}$ emulsion & - & [81] \\
\hline & PEG-PPG-PEG & PLGA & $\mathrm{O} / \mathrm{W}$ emulsion & Human growth hormone & [82] \\
\hline & PBS & PLGA & $\mathrm{W} / \mathrm{O} / \mathrm{W}$ double emulsion & - & [83] \\
\hline & Ammonium bicarbonate & PLGA & $\mathrm{W} / \mathrm{O} / \mathrm{W}$ double emulsion & - & [84] \\
\hline & Ammonium bicarbonate & PLLA & Emulsion precipitation & Insulin & [85] \\
\hline & $\begin{array}{l}\text { Ammonium bicarbonate, } \\
\text { sodium hydroxide }\end{array}$ & $\begin{array}{l}\text { PLGA, } \\
\text { PLA }\end{array}$ & Microfluidic method & 6-Coumarin & [49] \\
\hline & Ammonium bicarbonate & Leucine & Spray drying & Meloxicam & [86] \\
\hline & $\alpha$-cyclodextrin/PEG & PLGA & $\mathrm{W} / \mathrm{O} / \mathrm{W}$ double emulsion & Rhodamine $\mathrm{B}$ or melatonin & [87] \\
\hline & $\begin{array}{l}\text { Surfactants: sorbitan } \\
\text { trioleate, sorbitan } \\
\text { sesquioleate, sorbitan } \\
\text { oleate, Pentaoleic acid } \\
\text { hexaglycerin ester, } \\
\text { polyoxyethylene sorbitan } \\
\text { monooleate }\end{array}$ & PGMA & Suspension polymerization & - & [88] \\
\hline & Supercritical $\mathrm{CO}_{2}$ & P(TRIM) & Suspension polymerization & - & [89] \\
\hline \multirow[t]{4}{*}{ Osmogen } & Bovine serum albumin & PLGA & $\mathrm{W} / \mathrm{O} / \mathrm{W}$ double emulsion & $\begin{array}{l}\text { Insulin and vascular } \\
\text { endothelial growth factor }\end{array}$ & [79] \\
\hline & Sodium chloride & PLGA & $\mathrm{W} / \mathrm{O} / \mathrm{W}$ double emulsion & Risedronate sodium & [90] \\
\hline & $\begin{array}{l}\text { Sodium chloride, and } \\
\text { calcium chloride }\end{array}$ & PLA & $\mathrm{W} / \mathrm{O} / \mathrm{W}$ double emulsion & Brilliant blue & [91] \\
\hline & $\begin{array}{l}\text { Sodium chloride, } \\
\text { potassium chloride, and } \\
\text { sucrose }\end{array}$ & PLGA & $\mathrm{O} / \mathrm{W}$ emulsion & Insulin & [22] \\
\hline
\end{tabular}

\subsubsection{Microfluidics and spray drying techniques}

Among conventional porous particle preparation methods, the microfluidics-based technique represents a challenging means of producing porous particles with controlled final morphologies. An important component of microfluidic devices is a capillary system designed for droplet generation and controlling particle structures. Generally, a capillary device consists of coaxial assemblies fabricated from glass-based structures or polydimethylsiloxane (PDMS) [50, 51, 92]. Its capillary design must be simple and highly robust. The immiscible fluidic phases involve the breakup of droplets dripping under flow velocity through a small channel, generating monodisperse particles. The influence of tip size and flow rates also affect particle size [51]. In the microfluidics method, pore formation techniques are classified into 5 systems, including polymerization with and without porogens, using templates, flow reaction, self-assembly, and flow lithography [50]. Figure 6 illustrates the comparison of porous microsphere preparations using a 
conventional double emulsion solvent evaporation and a microfluidics device. The resultant porous microspheres exhibit higher porosity and controllable particle size with a narrow size distribution using the microfluidics method, compared to the double emulsion method. In the microfluidics process, the rate of dispersion is a key factor in controlling particle size, in which the diameter of PLGA particles decreases from 77 to $43 \mu \mathrm{m}$ at flow rates of 0.3 and $0.6 \mathrm{~mL} / \mathrm{min}$, respectively [49]. In addition, microfluidic emulsion polymerization is combined with UV irradiation in continuous flow photolithography, leading to fast response time and the stability of immobilized bioactive molecules in the resulting particles [93].

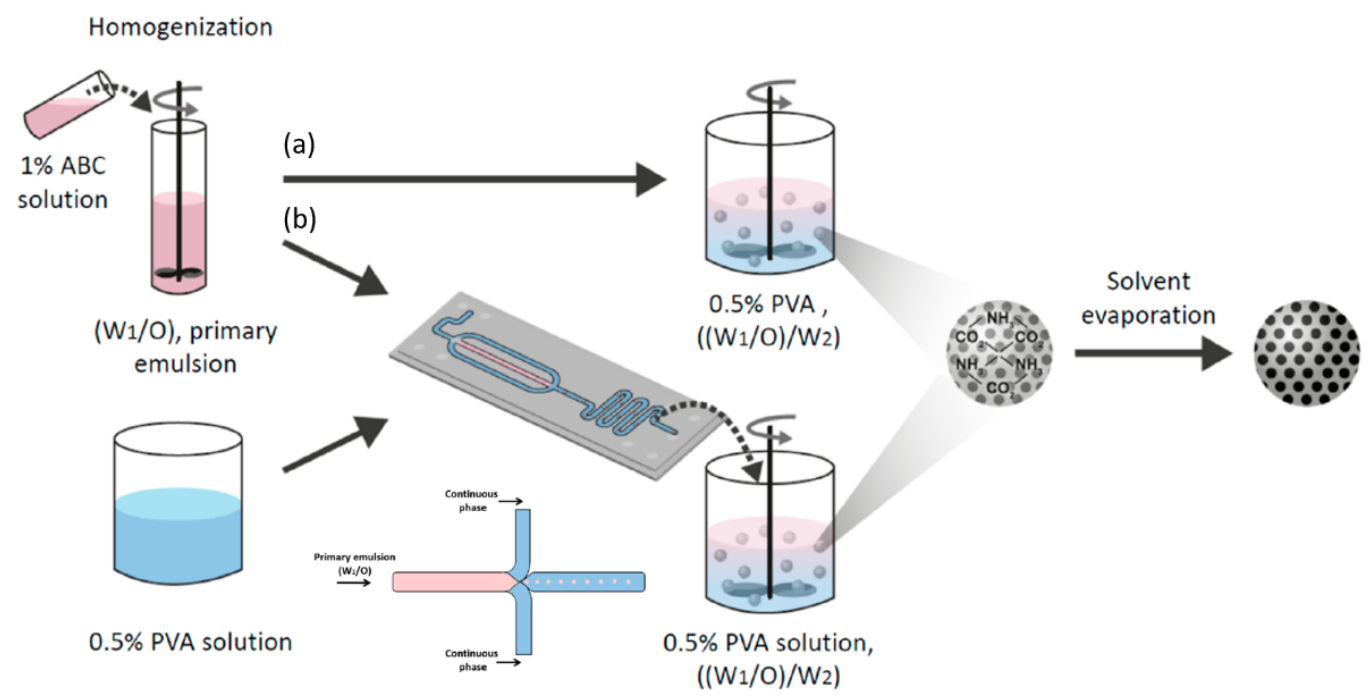

Figure 6 Schematic illustration of porous particle preparation by (a) $\mathrm{W}_{1} / \mathrm{O} / \mathrm{W}_{2}$ double emulsion solvent evaporation, in comparison with (b) the microfluidic method, along with its flow chip capillary design. Reprinted with permission from ref. [49].

In the large-scale production of particles with relatively narrow unimodal size distribution, spray drying has been shown to be an attractive method for fabricating pharmaceutical particles. The particles obtained have low density and precise particle diameters with a controlled morphology. The spray drying method typically involves 3 steps of processing: (i) atomization, (ii) droplet-to-particle conversion, and (iii) particle collection [55]. Initially, precursors, including polymer, porogens, and templates are homogenously mixed before spraying. Then, the precursor droplets are sprayed and rapidly vaporized to form solid particles by the driving force of the atomizer, for example, ultrasonic or fluid nozzles. Finally, the porous particles are obtained [47, 55]. The template used is removed by solvent leaching or heat treatment [94]. Porous hyaluronic 
acid particles with controllable pore size were fabricated by using a spray drying method and polystyrene templated particles. The obtained particles were 0.5 to $5 \mu \mathrm{m}$ with pore sizes in the range of 100 to $300 \mathrm{~nm}$ [94]. Further modifications of the process conditions or the addition of pore-forming agent can produce particles with various shapes, such as spherical particles, hollow particles, porous particles, mushroom-like, and doughnut-shaped particles [55]. Peng et al. studied the key factors of outlet temperature and ammonium carbonate concentrations for the spray drying of porous particles. The average particles size of obtained particles was about $5 \mu \mathrm{m}$. The formation of porous particles was achieved by varying the outlet temperatures at 65,75 , and $85^{\circ} \mathrm{C}$. Nonporous particles were formed at the lowest temperature due to slow evaporation, while pressure and the fast evaporation rate of the highest temperature led to the collapse of shell structures. Increasing the porogen content also affects the pore size and pore structure (closed pores, interconnected pores, and pore fusion). Optimized conditions to produce nanoporous particles with a mean pore size of $6 \mathrm{~nm}$ were observed at an outlet temperature of $75{ }^{\circ} \mathrm{C}$ and $25 \mathrm{wt} \%$ porogen [95].

\subsection{Morphology and properties of porous particles}

Pores size and size distribution, structure, surface area, and volume also affect the loading efficacy and the release rate of drug molecules. Porous materials can be prepared by organic polymers, inorganic materials (e.g., silica, metal oxides, and silver), or hybrid materials (magnetic core-porous shell nanoparticles) [96, 97].

\subsubsection{Pore size}

Pores size is an important factor associated with drug loading capacity and molecules diffusion, due to steric hindrance and interaction inside the cavities [98, 99]. Porous particles are classified according to their pore size: micro (less than $2 \mathrm{~nm})$, meso $(2-50 \mathrm{~nm})$, macro $(50-200 \mathrm{~nm})$ and giga (larger than $200 \mathrm{~nm}$ ) [100]. Mesoporous silica nanoparticles (MSNs) with three dimensional structures have unique properties and tunable pore size. The effect of pore size of an MSNs loaded with an anticancer drug (doxorubicin, DOX) was reported [101]. A pore size difference from 2.3 to $8.2 \mathrm{~nm}$ resulted in the increase of loading capacity from 8 up to 21\% [101]. In case of pore diameter smaller than the drug molecule, the drug cannot access into the cavity. This suggests that increasing pore size lead to easier drug absorption and entrapment inside the pores. In addition, the chemical bonding or surface charge between drug and porous particles also affect the loading capacity. In this study, DOX and MSNs dissolved at neutral pH (PBS pH = 7.4) 
were positively charged of amino groups and negatively charged of silanol groups, respectively. Therefore, the electrostatic interaction between DOX and MSNs enhanced the loading capacity of DOX [101]. Sharma et al. investigated the four morphologies of PLA microspheres, which are non-porous, microporous, mesoporous, and macroporous structures for biotherapeutic release in lung. Variable pore sizes of microspheres explored the different mechanisms of release. Macroporous microspheres (pore sizes $\geq 100 \mathrm{~nm}$ ) demonstrated high initial burst release and complete release from the porous structure, while non-porous, microporous, and mesoporous structures showed low encapsulation efficiency and slow release [102].

\subsubsection{Pore structure}

In terms of geometry, pores are divided into two types. An open pore is interconnected to the external surface, and acts as a passage to allow active molecules passing through the outside. In contrast, a closed pore is a void isolated from the external surface [103]. Open pores show outstanding properties, such as low density, high surface area, and fast release rate. They are more effective carriers for drug delivery systems since they show higher transfer capacity than closed pores. Bae and coworkers reported the influence of different morphologies of open-pore and closed- pore microspheres on their release profiles of dexamethasone. PLGA microspheres were prepared by using a double emulsion solvent evaporation method by adapting hydrogen peroxide as a porogen to produce the internal pore. A high amount of hydrogen peroxide promotes porous structures with an initial burst release of $60 \%$, and complete release in 28 days, while the internal closed pore particles were produced at a low concentration of porogen and presented a slow release rate [104]. As shown in Figure 7, the synthesis method strongly affects pore morphology. Porous microspheres were prepared by double emulsion solvent evaporation using ammonium bicarbonate as a porogen $[105,106]$. A specific combination of polymer molecular weight, volume ratio of aqueous to organic phases, homogenization speed, and porogen concentration led to cagelike microspheres with high porosity $(>93 \%)$ and large pore size. This structure is a threedimensional porous PLGA scaffold (Figure 7a) [24]. Porous PLGA microspheres with a spongelike skeleton was also obtained by ammonolysis. The diffusion of ammonia transferred to an aqueous phase resulted in numerous voids in both internal and external matrices (Figure 7b) [107]. Generally, the formation of golf ball-like microspheres can be achieved by using seeded polymerization and Pickering emulsion. Golf ball-like PLGA microspheres were fabricated by an oil-in-water emulsion with the addition of an organic phase-change material (PCM) for building 
specific morphologies (Figure 7c) [108]. Volatile PCM droplets play a role as a nonsolvent located in the PLGA interphase [108]. Self-assembly hydrophobic/hydrophilic porous particles were synthesized by a double emulsion interfacial polymerization [108]. Heterostructure-enabled separation particles, produced from poly(styrene-divinyl benzene)-poly(acrylic acid) (PSDVBPAA) were synthesized by a double emulsion interfacial polymerization process. The spherical porous particles were formed by turning the hydrophilic side chains of PAA to outside the particles and inside the voids, while hydrophobic chains of PSDVB constituted the matrix. The interconnected porous structure was obtained after interfacial polymerization (Figure 7d) [109].

\subsubsection{Surface area}

Surface area is a significant parameter that involves pore size and plays a key role in the absorption of active ingredients. For instance, porous chitosan microspheres were prepared by a water/oil emulsion using agarose as a pore-forming agent [110]. These porous microspheres provided a higher surface area of $246 \mathrm{~m}^{2} \mathrm{~g}^{-1}$, compared to $55.65 \mathrm{~m}^{2} \mathrm{~g}^{-1}$ for non-porous microspheres, as investigated by the BET method. The modified surface property of chitosan porous particles presented a hierarchical or interconnected porous structure and excellent adsorption of $302 \mathrm{mg} . \mathrm{g}^{-1}$ bovine hemoglobin within $15 \mathrm{~min}$ [110]. Cong et al. studied the effect of Span 80 on the morphologies of poly(glycidyl methacrylate-divinylbenzene) (PGMA-DVB) microspheres by using seed emulsion polymerization [75]. The pore size distribution and BET surface area of the product depended on the amount of Span 80: those without Span 80 exhibited the smallest pore size $(10 \mathrm{~nm})$ and a surface area value of $325 \mathrm{~m}^{2} \mathrm{~g}^{-1}$. In contrast, those produced with $0.6 \mathrm{ml}$ of Span 80 presented a microporous morphology with an average pore size of $12 \mathrm{~nm}$ and a surface area of $192 \mathrm{~m}^{2} \mathrm{~g}^{-1}[75]$.

\subsubsection{Pore volume}

Pore volume is directly related to surface area and drug loading capacity. Qiao and coworkers reported that by increasing the amount of pore-forming agent, a large number of voids were obtained. The increase in the porogen weight ratio from 0 to $15 \%$ led to an increase in the pore volume from 0.02 to $0.11 \mathrm{~cm}^{3} \mathrm{~g}^{-1}$ [110]. Another study of an MSN loaded with an anticancer drug showed that the surfactant concentration promoted the change of the pore volume from 0.48 to $1.55 \mathrm{~cm}^{3} \mathrm{~g}^{-1}$.[111] The largest pore volume and the highest surface area also led to the highest drug loading content of $57.2 \%$ [111]. 

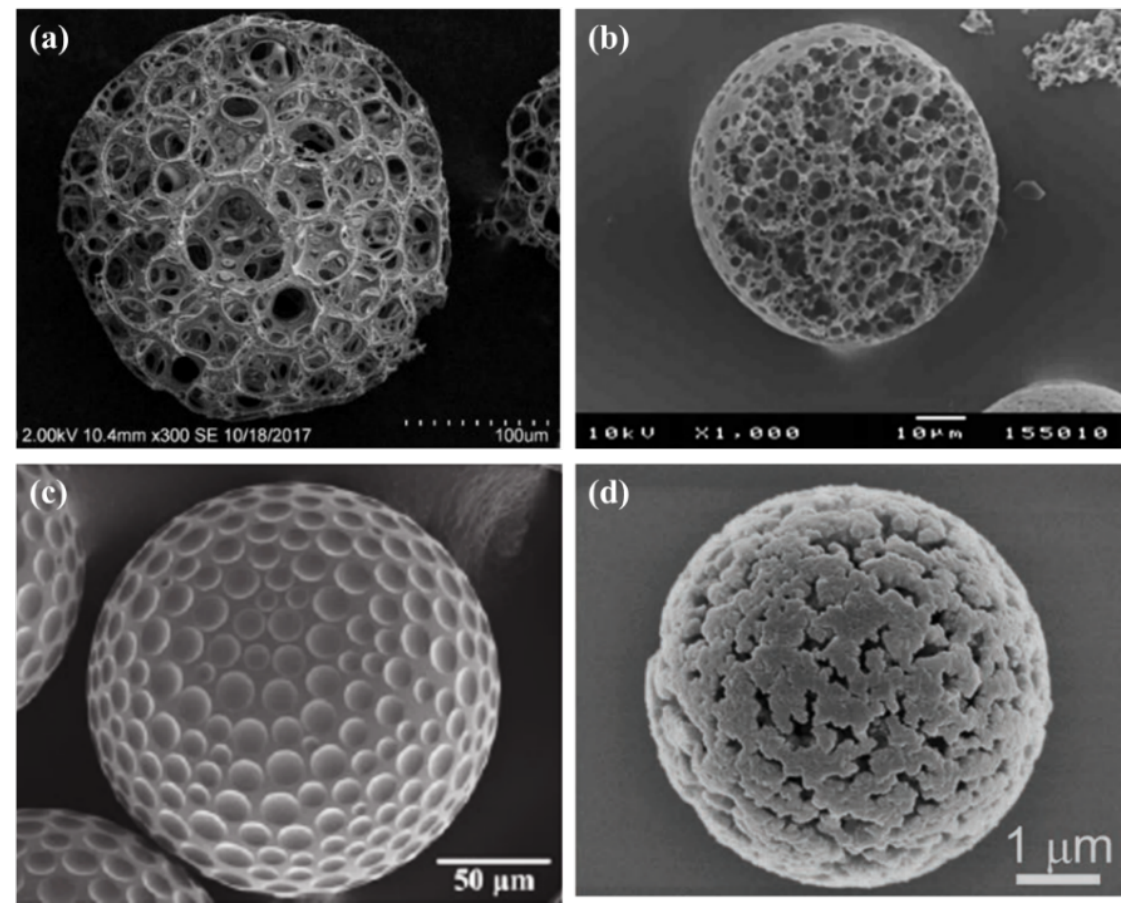

Figure 7 Examples of interconnected porous particles: (a) cage-like PLGA microsphere, Reprinted with permission from ref. [24]; (b) sponge-like PLGA microsphere, Reprinted with permission from ref. [107]; (c) golf ball-like microsphere, Reprinted with permission from ref. [108]; (d) interconnected pore network of PSDVB-PAA microspheres, Reprinted with permission from ref. [109].

\section{Stimuli-responsive gating porous particles}

Smart drug delivery carriers have been designed to accomplish controlled release formulations, as this can respond to physiochemical stimuli in their environment. Functional responsive porous particles can be monitored and their drug-release through the specific target can be controlled. Porous particles can effectively encapsulate drug molecules, magnetic nanoparticles, and fluorescent agents. The outer surface can be modified with specific antibodies, ligands targeting the cell surface, and anti-adhesive molecules. Furthermore, they can be synthesized or functionalized by responsive molecules for the precise control of open/closed pore structures at specific sites (Figure 8). The stimuli particles can respond simultaneously depending on the inherent stimuli of the human body or external stimuli, including $\mathrm{pH}$, temperature, enzymes, redox reagents, light, and magnetic field. Multifunctional integrated stimuli responsive polymers also improve their therapeutic efficacy and their capacity to deliver in a regulated manner for specific 
treatments. Table 3 summarizes the list of currently reported articles on stimuli-responsive porous particles.

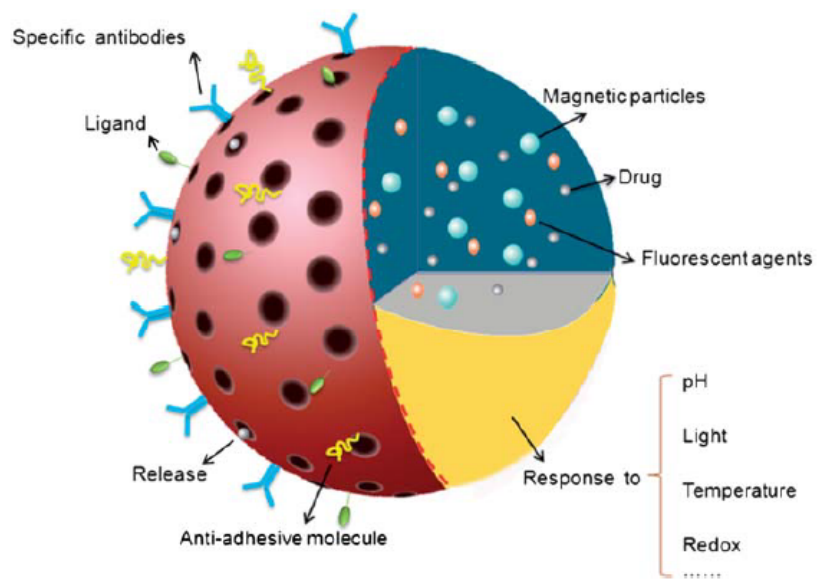

Figure 8 Schematic demonstration of mulifuntional stimuli-responsive porous paticle-loaded therapeutics and controlled release to specific target. Reprinted with permission from ref. [64].

\subsection{Types of gating structure}

The major types of gating structures are described by using MSNs as a core model, as illustrated in Figure 9 [39, 41]. Various gatekeepers show the "open/close" mechanism for preventing drug diffusion before delivery to the target. The gatekeepers are functionalized or bonded onto the surface of the porous carriers. Originally, the drug molecules are blocked, and unable to pass out of the pore host. The stimuli environment triggers the deformation of the gatekeeper, resulting in drug release [112]. The major types of gating structures include:

Structure I: Nanoparticles (NPs). Small size NPs (mostly inorganic NPs, e.g., Au NPs, Ag NPs, CdS NPs, $\mathrm{Fe}_{3} \mathrm{O}_{4}$ NPs, and ZnO NPs) are attached to the external pores of MSNs by ionic bonding interaction. External stimuli, such as $\mathrm{pH}$, redox potential and temperature can break these chemical bonds.

Structure II: Macrocyclic organic molecules. Organic molecules (cyclodextrin, cucurbit [6] uril, and dibenzo-24-crown-8) with bucket or crown shapes act as cages to immobilize stalks on the pores of MSNs. The cage can then be disassembled by external stimuli to release the encapsulated drug. 
Structure III: Liner molecules. Stimuli sensitive linear polymers are grafted around the surfaces of external pores. The molecules act as a switch gate to open/close pores when the system is stimulated.

Structure IV: Multi-layer shell coating. Stimuli-responsive polymers, biomolecules or polyelectrolyte multilayers are coated on the surface of MSNs by a layer-by-layer (LbL) deposition technique.[113] In the stimuli environment, the multilayer polymer chains are broken into small fragments, leading to drug diffusion.

Structure V: Pore modification. Only the interior pores of MSNs are modified by specific functional groups, stimuli-responsive polymers or nanoimpellers. These act as obstructions to trap the drug inside the pores.

$\begin{array}{ll} & \mathrm{Au} \text { NPs } \\ \text { Structure I } & \mathrm{CdS} \text { NPs } \\ \text { nanoparticles } & \mathrm{Fe}_{3} \mathrm{O}_{4} \mathrm{NPs} \\ \text { (NPs) } & \mathrm{ZnO} \mathrm{NPs}\end{array}$

Structure II macrocyclic organic molecules
Cyclodextrin (CD) Cucurbit[6]uril (CB[6]) Dibenzo-24-crown-8 (DB24C8)
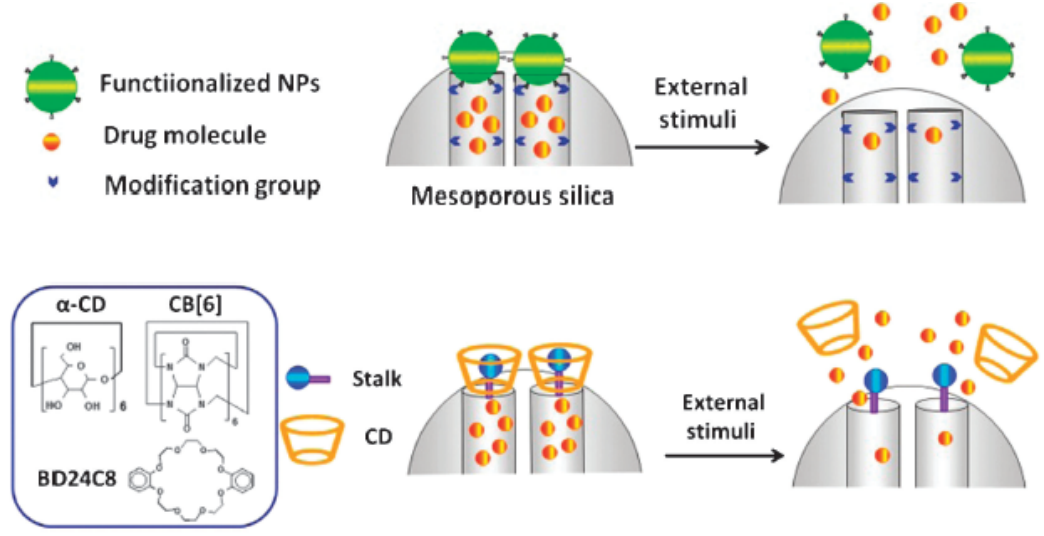

Liner polyamine

Structure III liner molecules

Saccharide derivative

Liner polymer

Peptide sequence

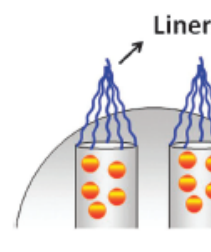

ner molecules
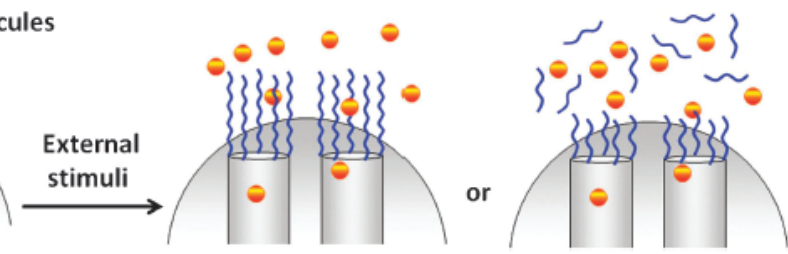

$\begin{array}{ll}\text { Structure IV } & \begin{array}{l}\text { Polymer layers } \\ \text { Biomolecules }\end{array} \\ \text { multilayers } & \text { Polyelectrolyte } \\ \text { shell coating } & \text { multilayers }\end{array}$

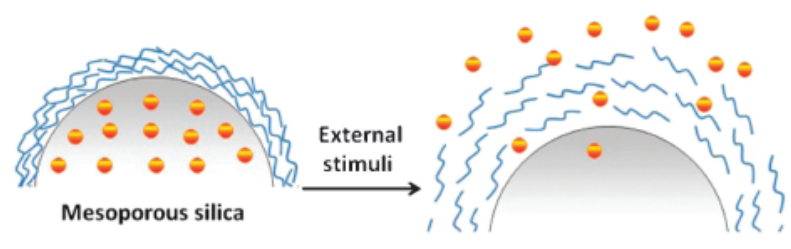

(a)

Functional molecule

Structure V Polymer pores Azobenzene derivatives impeller

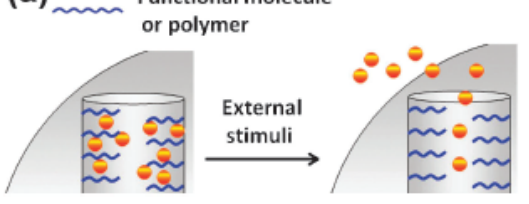

(b) مهم Nanoimpeller

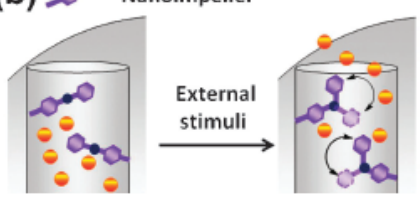

Figure 9 Schematic gating structures of mesoporous silica particles illustrated by types and examples of stimuli-responsive gates. Reprinted with permission from ref. [41]. 
The development of stimuli-responsive drug delivery systems increases drug carrier performance for remotely controlled action at the target site. Stimuli-responsive polymers can undergo structural transformation, self-assembly or chemical cleavage when triggered [114]. Stimuli-responsive drug delivery systems are categorized into two types: exogenous and endogenous stimuli. Exogenous stimuli are triggered by external factors, such as heat, light, magnetic field, and ultrasound. These stimuli are easily triggered for remotely-controlled drug delivery to the target after the administration of drug-loaded particles. This ensures that the carriers can release the drug at the target site at the right time [115]. On the other hand, endogenous stimuli provide significant benefits for diseased tissues in the microenvironment, including $\mathrm{pH}$ variation, redox state, different levels of glutathione (GSH), blood glucose level, and specific enzyme triggers $[114,116]$. Therefore, endogenous stimuli-responsive drug delivery systems can reduce side effects, and serve as more effective therapeutics [117].

\subsection{Exogenous stimuli-responsive gates}

Drug delivery is triggered by external physical stimuli. Common exogenous stimuli, such as temperature, light, magnetic nanoparticles, and ultrasound can induce shrinking or swelling transitions of the polymer gates utilized to obtain "close to open" switching pores.

\subsubsection{Thermo-responsive gates}

The thermo-responsive polymeric gate is one of the most attractive candidates, because of its specific sol-gel phase transition temperature. The difference between the environment and the body's temperatures stimulates the switchable trigger to allow drug release. Generally, the polymers in this case are categorized into two classes: polymers with a low critical solution temperature (LCST) undergo hydrophilic to hydrophobic transition, whereas polymers with an upper critical solution temperature (UCST) exhibit the opposite transition [5, 118, 119]. Varieties of temperature-sensitive polymers have been examined for use in drug delivery, synthetic or natural polymers; poly( $N$-isopropyl acrylamide) (PNIPAM), poly( $N$-vinylcaprolactam) (PVCL), poly( $N$-vinylalkylamide), poly(2-hydroxyethylmethacrylate) (PHEMA), pluronic, chitosan, hyaluronic acid, polypeptide, and gelatin [120]. PNIPAM is a well-known and largely employed thermo-responsive polymer. This polymer is water soluble with an LCST of around $32^{\circ} \mathrm{C}$. Below its LCST, PNIPAM is swollen, due to hydrogen bond formation between amide groups and water molecules, hence the pores are closed. When the temperature is increased above the LCST, the 
polymer segments become hydrophobic and shrink, leading to pore opening and the release of the encapsulated drug to the medium (Figure 10a) [27, 120, 121]. In addition, further modifications of PNIPAM properties can be achieved, in particular its LCST can be increased by the copolymerization of PNIPAM with different monomers, according to specific applications [122, 123]. Jadhav et al. developed thermoresponsive polymeric gates from random copolymers of NIPAM with acrylamide (AM), i.e., (poly(NIPAM-co-AM) copolymers) grafted in the inner MSN pores. The LCST value of the copolymers was raised to $41^{\circ} \mathrm{C}$. Antioxidant rutin was encapsulated in these thermoresponsive gate particles. When the temperature was increased to $45^{\circ} \mathrm{C}$, above the LCST of the copolymers, the sensitive polymer chains collapsed to open the pores, resulting in the release of rutin [123].

\subsubsection{Light-responsive gates}

Light- or photo-responsive gates can achieve drug release by external light irradiation at a specific wavelength, such as ultraviolet (UV), visible light, and near-infrared (NIR). According to their isomerization mechanisms, photo-responsive polymers are divided into reversible and irreversible behaviors [8]. Reversible photo-responsive polymers can transform into cyclic cistrans isomers without bond cleavage, for example, azobenzene can change from trans to cis configurations, in response to UV light at $351 \mathrm{~nm}$, with the distance of para carbon atoms decreasing from 9.0 to $5.5 \AA$ (Figure 10b) [27, 124]. Yuan et al. reported the photosensitive gating of MSNs using azobenzene-modified DNA molecules. The modified photoresponsive gate is immobilized at the pore mouth of MSNs. Rhodamine 6G, a model drug, was encapsulated within the porous particles to evaluate their controlled release behavior. Under visible light (450 nm), drug release was not observed due to the closed pore structure. However, drug release occurred when the gate was exposed to a UV range of $(365 \mathrm{~nm})$ [125]. Another azobenzene derivative was employed to act as a valves by bonding onto the outer surface of porous particles to prevent drug release. Azobenzene can bind with cyclodextrin (CD) in the trans configuration through van der Waals interaction, and debind in the cis configuration when being irradiated with UV light [126, 127]. Regarding irreversible photo-responsive polymers, during light induction the chemical bond is cleaved to switch from hydrophobic to hydrophilic isomers, such as spiropyan, coumarinyl and $o$-nitrobenzyl.[8] Despite the advantages, the use of light irradiation to trigger drug release may be limited by the depth of light penetration at deep tissue sites [128]. 


\subsubsection{Magnetic-responsive gates}

Magnetic nanoparticles (MNPs) have attracted interest in biomedical applications, due to their targeted delivery platform and capacity for controlled therapeutic release, by applying an external magnetic field. Superparamagnetic nanoparticles are typically used as magneticresponsive gates by nanocapping (structure I) or incorporatiion with other responsive polymers, such as pH-responsive or temperature responsive polymers [124, 129]. For example, pHresponsive nanocomposites of magnetic mesoporous silica were developed for hyperthermia cancer treatments [6]. In this system, $\beta$-thiopropionate-poly(ethylene glycol) acts as a $\mathrm{pH}$ gatekeeper, and can be hydrolyzed for fast release behavior at $\mathrm{pH} 5.8$ [130]. The dual-responsive gating particles of MNPs and temperature-responsive PNIPAM can control the close/open gates through the application of a magnetic field, as the MNPs generate thermal energy, inducing conformation changes of the thermo-responsive polymer (Figure 10c) [131].

(a)

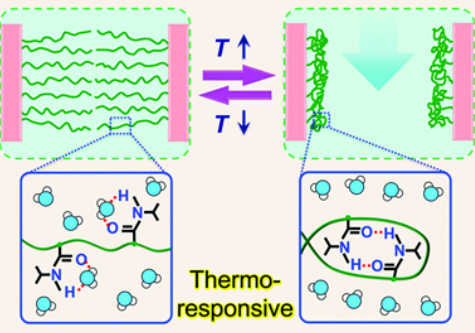

(b)

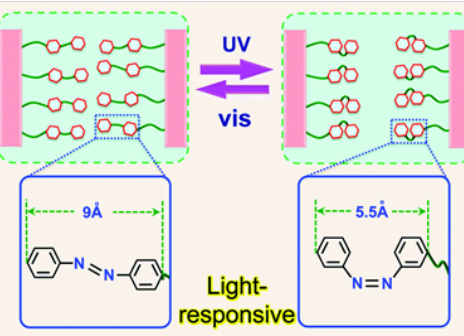

(c)

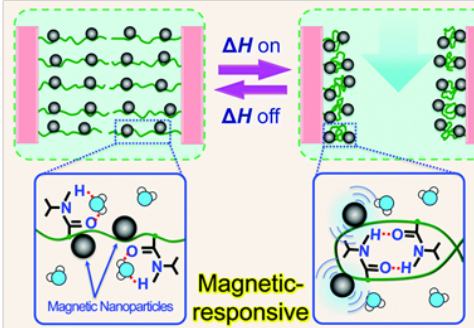

Figure 10 Smart gating model in the presence of external stimuli: (a) temperature, (b) UV light, and (c) magnetic field. Modified and reprinted with permission from ref. [27].

\subsubsection{Ultrasound responsive gates}

Ultrasound is a powerful physical modality for drug delivery and medical treatment. Ultrasound enhances the permeation of active ingredients through deep tissues with controlled frequency. Moreover, it can induce thermo-induction, mechanical stimulus or gas vaporization (bubble) for safety therapy [132]. The ultrasound parameters, including frequency, power, cycle, and exposure time are optimized for triggering drug release at a specific target. Paris et al. studied the utilization of 2-tetrahydropyranyl methacrylate (THPMA) as an ultrasound-responsive polymer gatekeeper for MSNs. When ultrasound was applied, a phase transformation of THPMA occurred, changing it from hydrophobic to hydrophilic form. Figure 11 shows that the hydrolysis of ultrasound-responsive polymer leads to gate opening, resulting in the release of fluorescein to the medium, by employing ultrasound at $1.3 \mathrm{MHz}$ and $100 \mathrm{~W}$ for $10 \mathrm{~min}$ [133]. 


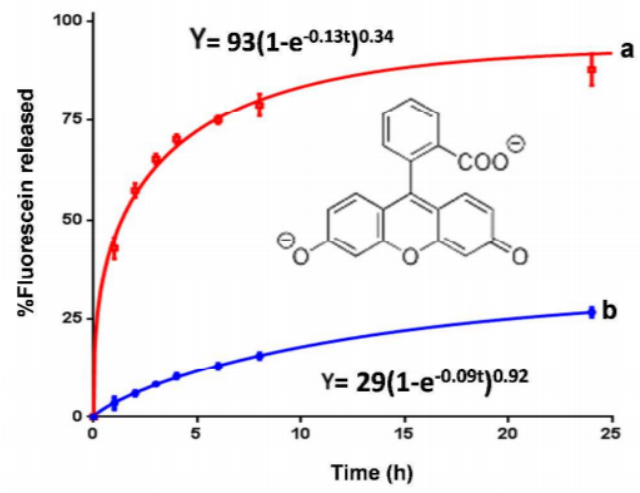

Figure 11 The release profiles of fluorescein from hybrid mesoporous silica nanoparticles in PBS solution: with (a) ultrasound exposure and (b) without ultrasound. Reprinted with permission from ref. [133].

\subsection{Endogenous stimuli-responsive particles}

The stimuli-responsive carriers are sensitive to biochemical origins and cellular levels in changing endogenous stimli, such as $\mathrm{pH}$, redox, enzyme, and glucose. The stimuli can trigger drug release at targeted tissues.

\subsection{3 pH responsive gates}

Among various types of stimuli, $\mathrm{pH}$-sensitive drug carriers are those most commonly used for the development of controlled release systems. Different locations of human organs have distinctly different $\mathrm{pH}$ values, for example the gastrointestinal system of the stomach $(\mathrm{pH} \approx 1.0$ 3.0 ), intestine $(\mathrm{pH} \approx 6.5-8.0)$, and blood $(\mathrm{pH} \approx 7.4)$. Pathogenic conditons, such as tumors and bacterial infections, lead to changes in $\mathrm{pH}$ level from neutral to slightly acidic $(\mathrm{pH} \approx 6.8)[41,134]$. The development of porous particles can be achieved through surface functionalization with $\mathrm{pH}$ responsive triggers as gatekeepers by using polyelectrolytes, supramolecular valves, $\mathrm{pH}$-sensitive linkers, and acid-decomposable inorganic materials [124, 134, 135]. pH-sensitive carriers have the ability to differentiate slight $\mathrm{pH}$ changes in some diseases, such as tumors, and inflammed tissues. Lin et al. designed $\mathrm{pH}$-sensitive MSNs using acetelated-dextran as a gate for the controlled release of anticancer drugs. In a neutral environment $(\mathrm{pH} 7.4)$, hydrophobic dextran acted as a gate to block drugs entrapped inside MSNs. In acidic conditions, however, hydrolyzed dextran transforms into hydrophilic state, which triggers the release of DOX [136]. 


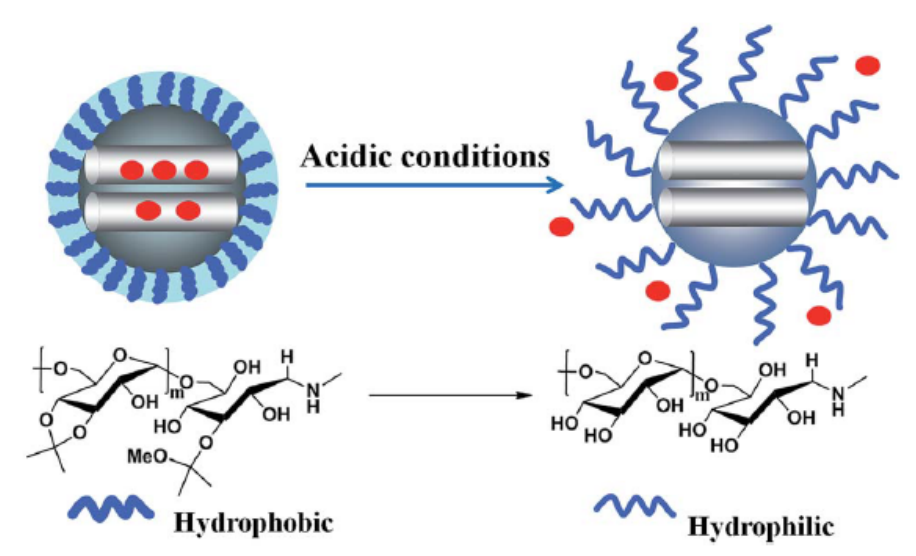

Figure 12 Schematic illustration of the $\mathrm{pH}$ triggered drug release of acetalated-dextran/ mesoporous silica nanoparticles. Reprinted with permission from ref. [136].

\subsubsection{Redox responsive gates}

Among the variety of stimuli-responsive species for drug delivery systems, redoxresponsive carriers can effectively trigger the targeted intercellular environment. In this regard, glutathione (GSH) is the most abundant reducing agent; the cleavage of GSH produces disulfide bonds (S-S). The stability of the disulfide linkages can block the encapsulated drug from the external environment, while their reduction in the tumor environment leads to bond breaking and drug release. Disulfide bonds acquire redox sensitivity [137]. The presence of high concentrations of GSH also affects the release rate of drug molecules due to completely cleaved disulfide bonds at the pores [138]. Redox-gatekeepers have been developed by using nanoparticles, supramolecules, and polymers for covering the pore structure [124]. Wang et al. successfully fabricated redox-responsive MSN by using polyethylene glycol (PEG) as a gatekeeper. PEG was grafted onto the external surface pores of modified MSN (SS-MSN) by condensation reaction between hydroxyl groups of PEG and carboxyl groups of SS-MSN through disulfide bonds, resulting in PEG-SS-MSN. Intracellular GSH is adequate to break disulfide bonds for releasing dyes (Figure 13) [139]. 


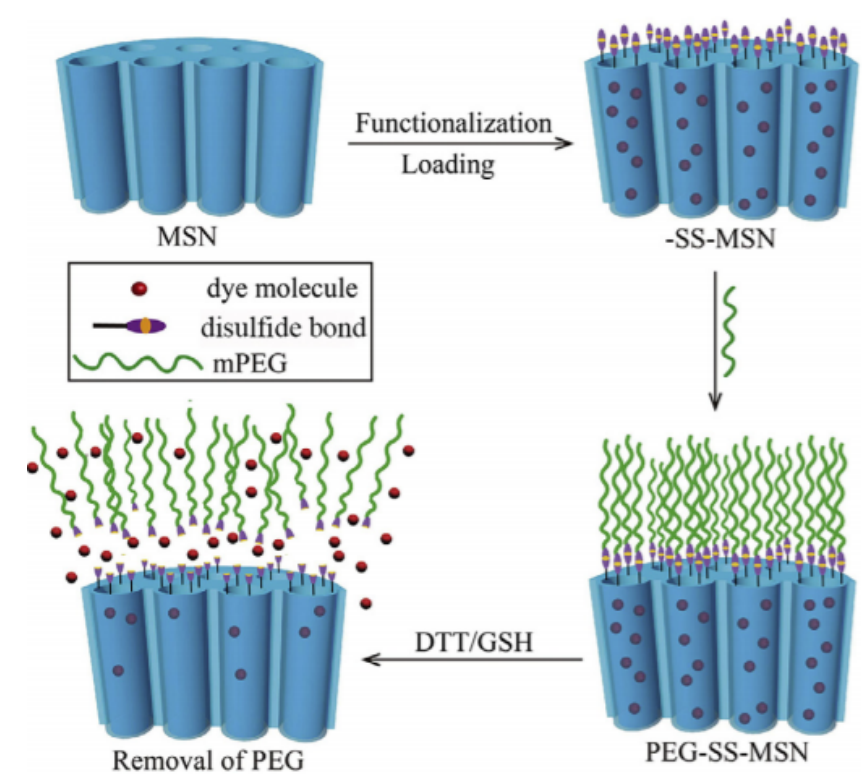

Figure 13 Schematic illustration of drug loaded redox-responsive carriers based on silica and PEG gatekeepers. Reprinted with permission from ref. [139].

\subsubsection{Enzyme-responsive gates}

Enzymes are biological catalysts produced by particular microorganisms. They can break down polymeric bonds, causing the disassembly of nanocarriers and allowing drug release in drugdelivery applications. Enzyme-responsive systems have been applied in the form of responsive gatekeepers on the nanovalves of porous silica nanoparticles [124, 140]. Nanoparticles can be modified with specific enzyme-labile linkages to trigger drug release and control the initial response time of the system. Sensitive peptide gatekeepers, i.e., succinic acid-glycinephenylalanine-leucine-glycine (SGFLG) sequence and transferrin were grafted onto MSN surfaces to encapsulate an anticancer drug (DOX) and photosensitizer (chlorine e6), as shown in Figure 14 [141]. Sensitive polypeptide gatekeepers induce gate opening and controlled drug release towards their degradation in a cathepsin $\mathrm{D}$ (protease) and low $\mathrm{pH}$ environment. In addition, this smart particle promotes photosensitivity to generate reactive oxygen species under NIR irradiation for specific chemotherapy and photodynamic therapy in cancer treatments. Other enzyme-responsive nanoparticles were reported to improve diagnostic features for cancer treatments and inflammation. For example, supramolecular cyclodextrin, [142-144] and gold nanoparticles [145] combined with specific sensitive linkers were utillized to block nanopores. 

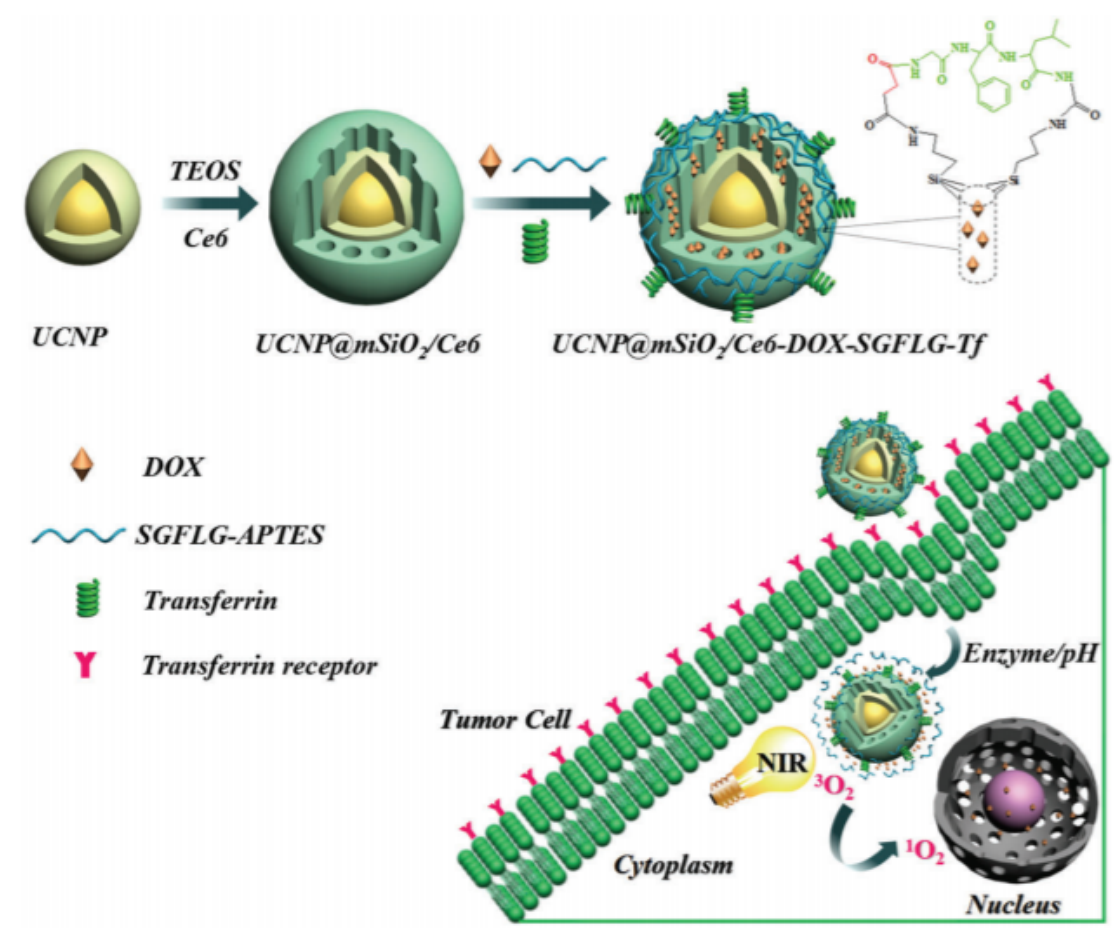

Figure 14 Dual enzyme/pH-responsive nanoparticles of DOX-loaded MSN with a SGFLG peptide gatekeeper. Reprinted with permission from ref. [141].

\subsubsection{Glucose-responsive gates}

Smart insulin delivery is a highly promising treatment for diabetes, which is a metabolic disorder leading to hyperglycemia. Glucose responsive compounds play an important role in the detection of the blood glucose level. They are mainly classified into 3 classes, including phenylboronic acid, concanavalin A, and glucose oxidase [146]. Phenylboronic acid (PBA) is a typical synthetic compound sensitive to rapid physicochemical changes in glucose response. PBA reacts reversibly with $D$-fructose, $D$-galactose and 1,2-cis-/1,3diols, resulting in transformation from hydrophobic to hydrophilic form. This trigger can effectively induce the release of insulin [147]. Concanavalin A (Con A) is a lectin that contains four sugar-binding sites: $\alpha-D$ mannopyranose, $\alpha$ - $D$-glucopyranose, and the other ono-reducing sugars. This sensitive compound combines with Con A and other substances on the particles, resulting in the break down of their chemical structure and insulin release [148]. However, Con A possesses poor biocompatibility and instability.[146] A well-known enzyme for monitoring the blood glucose level is glucose oxidase (GOx). This consists of two subunits bonded with two prosthetic groups of flavin adenine dinucleotides. Cyclodextrain modified glucose oxidase (CD-GOx) was used as a gatekeeper grafted onto MSN for fluoresein isothiocyanate-labeled insulin (FITC-Ins) delivery [149]. Figure 
15 represents the design of the complex gatekeeper between CD-GOx and benzimidazol groups. When the particles are triggered by glucose in a medium, glucose is hydrolyzed into gluconic acid by the glucose oxidase enzyme, with the protonation of benzimidazol groups. This promotes the dethreading of gatekeeper complexes, leading to delivery insulin.

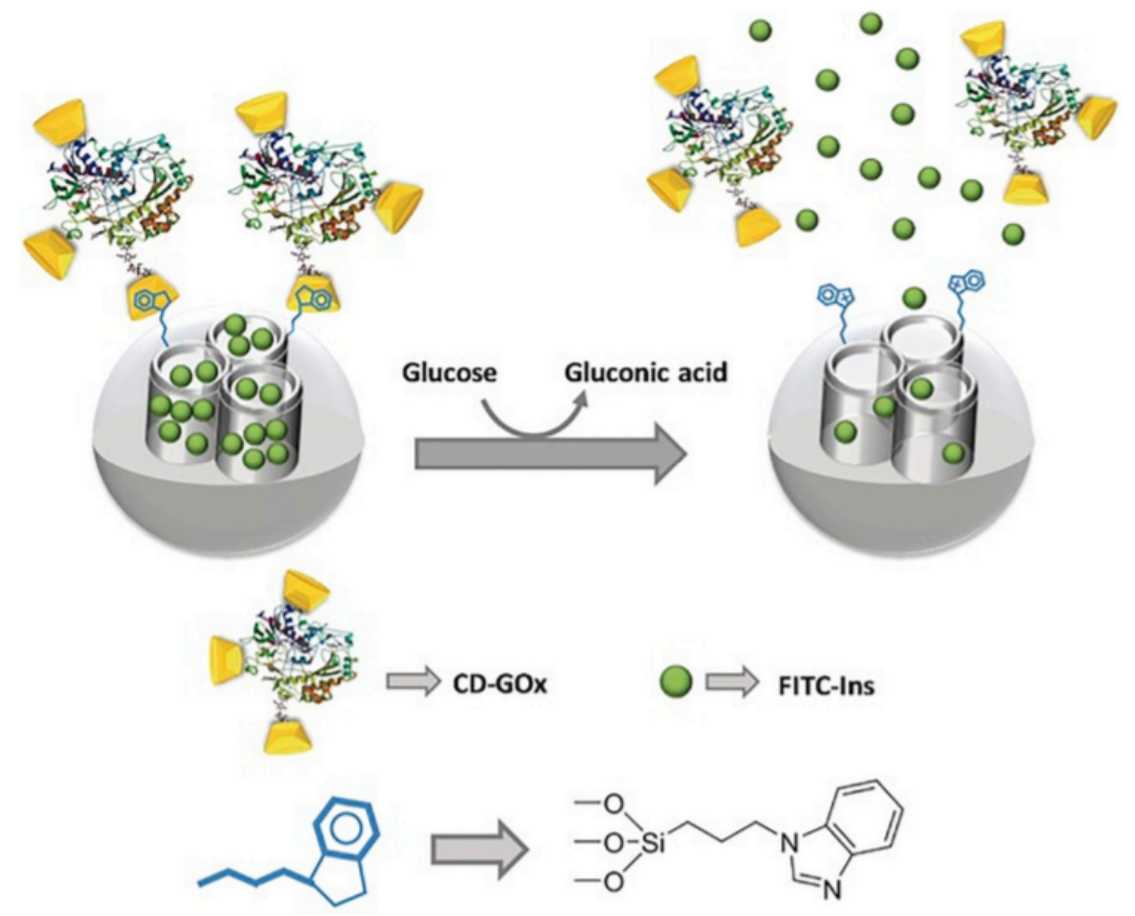

Figure 15 The glucose responsive drug delivery of fluorescein isothiocyanate-labeled insulinbased mesoporous silica nanoparticles. Reprinted with permission from ref. [149].

Table 3 Stimuli-responsive polymers and their corresponding stimulus.

\begin{tabular}{|c|c|c|c|c|}
\hline $\begin{array}{l}\text { Type of } \\
\text { stimulus }\end{array}$ & $\begin{array}{l}\text { Porous } \\
\text { particle }\end{array}$ & Gatekeeper & Objectives & Ref. \\
\hline Temperature & MSN & $\begin{array}{l}\text { Poly(ethylene glycol)/ } \\
\text { poly( }(\varepsilon \text {-caprolactone) } \\
\text { multiblock copolymer }\end{array}$ & $\begin{array}{l}\text { Copolymer gatekeeper response to heat-shock } \\
\text { stimuli for DOX release. }\end{array}$ & [150] \\
\hline Temperature & MSN & $\begin{array}{l}\text { Poly }(N \text {-isopropyl } \\
\text { acrylamide) }\end{array}$ & $\begin{array}{l}\text { Preparation of PNIPAM-grafted mesoporous } \\
\text { silica particles. }\end{array}$ & [151] \\
\hline Temperature & $\begin{array}{l}\text { Hollow } \\
\text { MSN }\end{array}$ & $\begin{array}{l}\text { Poly }(N \text {-isopropylacryl } \\
\text { amide) }\end{array}$ & $\begin{array}{l}\text { Synthesis of hollow MSN with PNIPAM } \\
\text { coating. }\end{array}$ & [152] \\
\hline Temperature & Gelatin & $\begin{array}{l}\text { Poly }(N \text {-isopropylacryl } \\
\text { amide) }\end{array}$ & $\begin{array}{l}\text { Grafted PNIPAM with gelatin microspheres } \\
\text { with reversible on/off switch for drug release. }\end{array}$ & [153] \\
\hline Temperature & Alginate & $\begin{array}{l}\text { Poly }(N \text {-isopropylacryl } \\
\text { amide })\end{array}$ & $\begin{array}{l}\text { Preparation of smart polysaccharide particles } \\
\text { with temperature dependent drug release. }\end{array}$ & [154] \\
\hline $\begin{array}{l}\text { Temperature } \\
\text {-Magnetic }\end{array}$ & MSN & $\begin{array}{l}N \text {-isopropylacrylamide/ } \\
\text { (Hydroxymethyl)acryla } \\
\text { mide copolymer }\end{array}$ & $\begin{array}{l}\text { Effect of grafting structure on fluorescein } \\
\text { release behavior, rendering opposite profiles. }\end{array}$ & [122] \\
\hline
\end{tabular}




\begin{tabular}{|c|c|c|c|}
\hline NIR light & MSN & Copper sulfide (CuS) & $\begin{array}{l}\text { CuS-capped MSN acted as NIR-responsive and } \\
\text { photothermally triggered DOX release. }\end{array}$ \\
\hline NIR light & PLA & Polypyrrole & $\begin{array}{l}\text { One-step preparation of NIR responsive porous } \\
\text { particles with conductivity and photo-thermo } \\
\text { conversion. }\end{array}$ \\
\hline UV light & MSN & $\begin{array}{l}\text { Cyclodextrin } \\
o \text {-nitrobenzyl }\end{array}$ & $\begin{array}{l}\text { Cyclodextrin and photocleavable linkers } \\
\text { blocked in MSN pores under UV light. }\end{array}$ \\
\hline Magnetic & PCL & $\begin{array}{l}\text { Magnetic } \mathrm{Fe}_{3} \mathrm{O}_{4} \\
\text { nanoparticles }\end{array}$ & $\begin{array}{l}\text { Magnetic/ PCL porous particles produced by } \\
\text { electrospray technique, and release rate } \\
\text { enhanced by external magnetic stimuli. }\end{array}$ \\
\hline Magnetic & MSN & $\begin{array}{l}\text { Superparamagnetic } \\
\mathrm{Fe}_{2} \mathrm{O}_{3} \text { nanoparticles }\end{array}$ & $\begin{array}{l}\text { Switchable DNA/MNPs as caps for blocking } \\
\text { fluorescein with on-off release behavior. }\end{array}$ \\
\hline Ultrasound & MSN & polyethylenimine & $\begin{array}{l}\text { Responsive nanocarriers exposed by ultrasound } \\
\text { for treating tumor cells. }\end{array}$ \\
\hline Ultrasound & MSN & $\begin{array}{l}\text { 2-Tetrahydropyranyl } \\
\text { methacrylate }\end{array}$ & $\begin{array}{l}\text { Ultrasound parameters studied for applying } \\
\text { nanocarriers inside LNCaP cells with high } \\
\text { fluorescein release rate. }\end{array}$ \\
\hline $\mathrm{pH}$ & MSN & Acetalated dextran & $\begin{array}{l}\text { Preparation of hydrophobic valves to entrap } \\
\text { DOX inside mesoporous silica. }\end{array}$ \\
\hline $\mathrm{pH}$ & MSN & $\begin{array}{l}\text { Poly(phenyl(4-(hydro } \\
\text { xylmethyl)phenyl)carba } \\
\text { mate) }\end{array}$ & $\begin{array}{l}\mathrm{pH} \text { responsive nanocarriers for potential cancer } \\
\text { treatment. }\end{array}$ \\
\hline $\mathrm{pH}$ & MSN & Chitosan & $\begin{array}{l}\text { Chitosan hydrogel capped over pores; insulin } \\
\text { penetrates through swollen hydrogel at } \mathrm{pH} 6.0 \text {, } \\
\text { while blocked at } \mathrm{pH} 7.4 \text {. }\end{array}$ \\
\hline $\mathrm{pH}$ & PLGA & Chitosan/alginate & $\begin{array}{l}\text { Layer-by-layer pH sensitive self-assembly } \\
\text { nanoparticles. }\end{array}$ \\
\hline $\begin{array}{l}\mathrm{pH}- \\
\text { Magnetic }\end{array}$ & MSN & $\begin{array}{l}\beta \text {-thiopropionate- } \\
\text { poly(ethylene glycol) }\end{array}$ & $\begin{array}{l}\text { DOX vehicles combined magnetic targeting, } \\
\text { and pore opening at } \mathrm{pH} 5.8 \text {. }\end{array}$ \\
\hline $\begin{array}{l}\mathrm{pH}- \\
\text { Ultrasound }\end{array}$ & MSN & polydopamine & $\begin{array}{l}\text { DOX released at low } \mathrm{pH} \text { values due to } \\
\text { degradation of polymer, while ultrasound } \\
\text { stimulated DOX released by cavitation effect. }\end{array}$ \\
\hline $\begin{array}{l}\mathrm{pH}- \\
\text { Magnetic- } \\
\text { Ultrasound }\end{array}$ & MSN & Dibenzo-crown ethers & $\begin{array}{l}\text { The release of DOX triggered by low } \mathrm{pH} \text { and } \\
\text { ultrasonic waves to break up electrostatic } \\
\text { interaction between supramolecular and metal } \\
\text { stalks. }\end{array}$ \\
\hline Redox & MSN & Glutathione & $\begin{array}{l}\text { Concentration of gatekeepers on MSN affects } \\
\text { the release rate of salicylic acid due to disulfide } \\
\text { bond cleavage. }\end{array}$ \\
\hline Redox & MSN & $\begin{array}{l}\text { Poly(ethylene glycol) } \\
\text { Glutathione }\end{array}$ & $\begin{array}{l}\text { Gating efficiency of glutathione and } \\
\text { polyethylene glycol on model drug release. }\end{array}$ \\
\hline Redox & MSN & Transferrin & $\begin{array}{l}\text { Transferrin-capped MSN nanocarrier designed } \\
\text { to control drug delivery via conjugating } \\
\text { disulfide bonds. }\end{array}$ \\
\hline $\begin{array}{l}\text { Redox- } \\
\text { NIR light }\end{array}$ & MSN & Gold nanoparticles & $\begin{array}{l}\text { Gold/MSN particles act as gatekeepers and } \\
\text { absorb NIR irradiation for inducing } \\
\text { photothermal therapy. }\end{array}$ \\
\hline $\begin{array}{l}\text { Redox- } \\
\text { NIR light }\end{array}$ & MSN & $\begin{array}{l}D \text { - } \alpha \text {-tocopherol } \\
\text { polyethylene glycol } 1000 \\
\text { succinate and cypate }\end{array}$ & MSN gate designed for antitumor drug. \\
\hline $\begin{array}{l}\text { Redox- } \\
\text { Enzyme }\end{array}$ & MSN & $\begin{array}{l}\text { Oxidized glutathione } \\
\text { Hyaluronic acid }\end{array}$ & $\begin{array}{l}\text { Modification of sealing pore drug carriers, drug } \\
\text { release by cleaving of disulfide bonds or } \\
\text { decomposition of hyaluronic acid. }\end{array}$ \\
\hline Enzyme & MSN & Cyclodextrin & $\begin{array}{l}\text { Cyclodextrin gatekeepers are sensitive to the } \\
\text { enzymatic activity of } \alpha \text {-amylase and lipase. }\end{array}$ \\
\hline
\end{tabular}




\begin{tabular}{|c|c|c|c|}
\hline Enzyme & MSN & $\varepsilon$-poly-L-lysine & $\begin{array}{l}\text { Two different types of } \varepsilon \text {-poly-L-lysine } \\
\text { anchored onto outer pore MSN with release }\end{array}$ \\
\hline Enzyme & MSN & Saccharide derivatives & $\begin{array}{l}\text { behavior in the presence of proteases. } \\
\text { Novel saccharide derivatives functionalized on } \\
\text { the pore outlets of MSN. Enzyme dependent } \\
\text { opening of saccharide gate and dye release. }\end{array}$ \\
\hline Enzyme & MSN & $\begin{array}{l}\text { Gold nanoparticles- } \\
\text { biotin }\end{array}$ & $\begin{array}{l}\text { Fabrication of gold nanoparticle-biotin } \\
\text { conjugate-capped MSN. }\end{array}$ \\
\hline $\begin{array}{l}\text { Enzyme- } \\
\text { pH }\end{array}$ & MSN & $\begin{array}{l}\text { Succinic acid-glycine-- } \\
\text { phenylalanine-leucine- } \\
\text { glycine (SGFLG) }\end{array}$ & $\begin{array}{l}\text { In vitro DOX release of peptide gatekeeper } \\
\text { depending on cathepsin } \mathrm{B} \text { enzyme } \\
\text { concentration and } \mathrm{pH} \text { value. }\end{array}$ \\
\hline Glucose & PLGA & $\begin{array}{l}\text { Poly(vinyl alcohol) and } \\
\text { poly(acrylamide phenyl } \\
\text { boronic acid-co-N- } \\
\text { vinylcaprolactam) }\end{array}$ & $\begin{array}{l}\text { Development of multilayer microspheres for } \\
\text { controlling blood sugar level to treat diabetes. }\end{array}$ \\
\hline Glucose & MSN & $\begin{array}{l}\text { Glucose oxidase (GOD) } \\
\text { catalase }\end{array}$ & $\begin{array}{l}\text { Design of controlled release of insulin by } \\
\text { multilayer coating on outlet pore particles. }\end{array}$ \\
\hline Glucose & MSN & $\begin{array}{l}\text { B-Cyclodextrin modified } \\
\text { glucose oxidase }\end{array}$ & $\begin{array}{l}\text { Development of glucose-sensitive compound } \\
\text { for insulin-controlled release. }\end{array}$ \\
\hline Glucose & MSN & $\begin{array}{l}\text { Gluconic acid-modified } \\
\text { insulin }\end{array}$ & $\begin{array}{l}\text { Synthesis of a glucose-responsive MSN with } \\
\text { double delivery system for both insulin and } \\
\text { cyclic adenosine monophosphate. }\end{array}$ \\
\hline $\begin{array}{l}\text { Glucose- } \\
\mathrm{pH}\end{array}$ & MSN & $\begin{array}{l}\text { Low molecular weight } \\
\text { gelator }\end{array}$ & $\begin{array}{l}\text { Controlled antidiabetic gel capped drug release } \\
\text { by glucose and } \mathrm{pH} \text { stimuli. }\end{array}$ \\
\hline
\end{tabular}

MSN $=$ mesoporous silica, MNPs $=$ magnetic nanoparticles, $\mathrm{DOX}=$ doxorubicin, $\mathrm{PLGA}=$ poly $($ lactic-co-glycolic acid), PNIPAM = poly $(N$-isopropylacrylamide), PLA = poly(lactic acid $)$, PCL = Poly $(\varepsilon$-caprolactone $)$.

\section{Potential roles in practical applications}

In the biomedical field, drug-loaded stimuli-responsive porous particles are being investigated intensively. The benefits of these particles are: (i) high drug loading efficacy, due to their high surface area and porosity; (ii) precise design of gatekeepers and their structures; (iii) stimuli-responsive drug release at specific targeted sites. The major challenges in drug delivery systems are to find strategies to achieve high drug loading capacity and stability in physiological environments. Stimuli triggered gatekeepers finally allow sustained release at optimal levels over prolonged time periods [176]. Most studies of drug-loaded stimuli-responsive particles involve an anti-cancer drugs, anti-inflammatory drugs, and inhalable drugs for pulmonary drug delivery. However, the biocompatibility of drug carriers is mainly necessary for clinical use because materials can interfere within the biological system. Particles may interact with the biological systems through various complex mechanisms at a cellular level and cause toxicity [177]. Surface modification of MSNs with hydrophilic polymers, like PEG gatekeepers can also reduce their protein adsorption and prevent nonspecific binding on surface particles [139, 178]. Therefore, 
biodegradable drug carriers and non-cytotoxic materials for gatekeepers require further investigation.

The development of responsive-drug carriers for chemotherapy demands sufficient drug release at the tumor location. Multiple endogenous stimuli carriers can be triggered by changing the microenvironment, including mild acidity, increasing intercellular glutathione levels, and enzyme overexpression, which are characteristics of tumor tissues [179, 180]. Therefore, the combination of internal stimuli and external stimuli, such as $\mathrm{pH}$, redox, enzyme, temperature, light, and magnetic-responsive drug carriers, are also required for improving drug controlled release performance [181]. A novel nanoporous platform presented multiple sensitive drug delivery systems with DOX-loaded MSN, coated with polydopamine (PDA) via disulfide bonds. PDA plays an important role as a photothermal therapy gatekeeper with outstanding characteristics, since it is highly $\mathrm{pH}$ sensitive, it is capable of absorbing NIR radiation, and it is biocompatible. At a neutral $\mathrm{pH}$, therapeutic drugs were blocked in MSN, but released at lower pHs. Figure 16 illustrates a redox/pH/NIR multi-responsive drug carrier, and their synthesis processes. Sustainable release was achieved at $\mathrm{pH} 5.0$ and with $10 \mathrm{mM}$ of GSH. The results from an in vivo study in mice showed that a synergistic effect of photothermal treatment and prolonged drug release was achieved by applying NIR irradiation to these particles. This led to the effective inhibition of tumor growth [182]. In another responsive porous particle system, modified $\mathrm{pH}-$ /redox-responsive MSN was prepared. DOX was entrapped in the MSN pores which were capped by hyaluronic acid-grafted-cyclodextrin (HA-g-CD) as a gatekeeper. The in vitro results indicated the excellent targeting ability of HA-g-CD nanocapsules against CD44 overexpressed cancer cells, the rapid release of DOX by the hydrolysis of benzoic imine bonds at low $\mathrm{pH}$, and the cleavage of disulfide bonds at high glutathione levels [183]. 
(a)

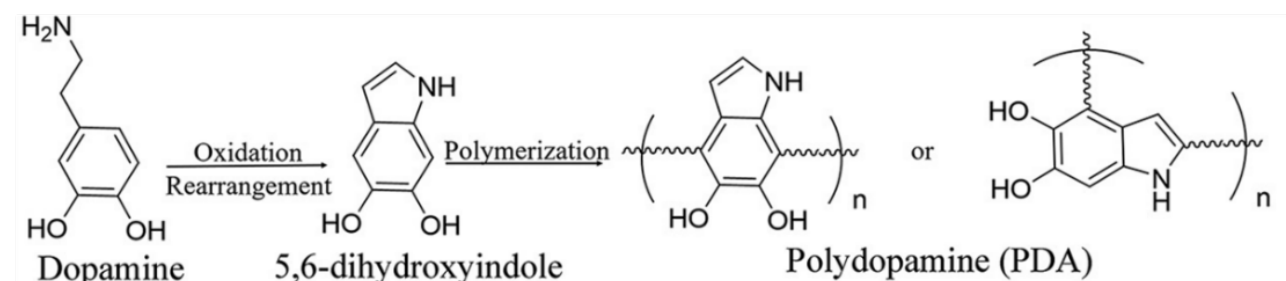

(b)

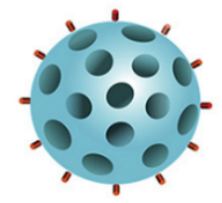

Polydopamine (PDA)
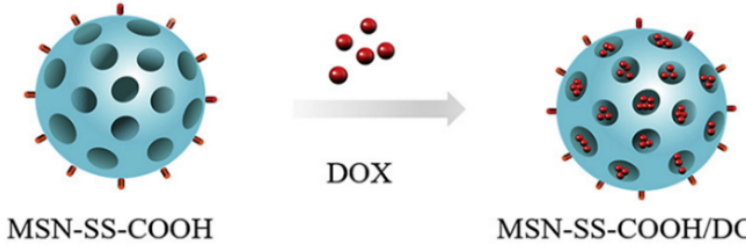

MSN-SS-COOH/DOX

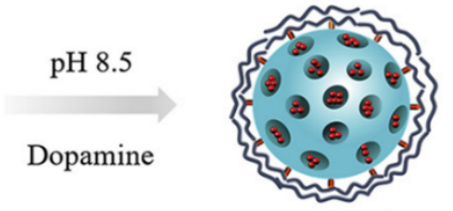

MSN-SS-PDA/DOX

(c)
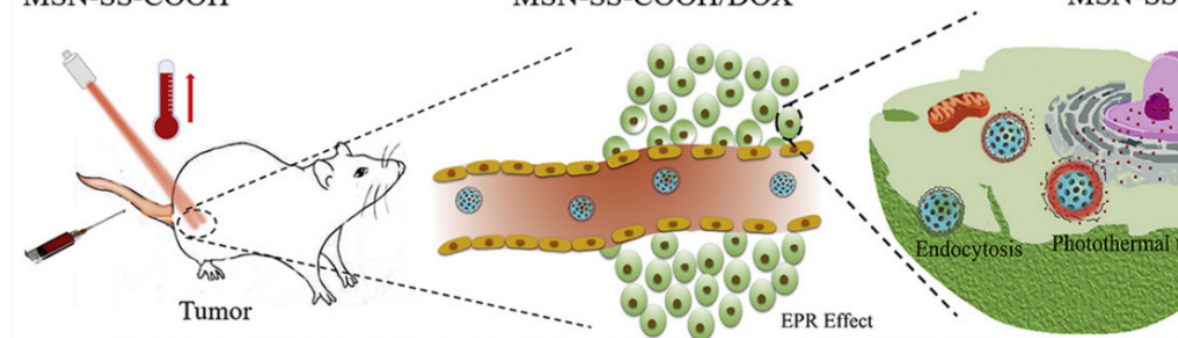

MSN

- DOX

- Disulfide bonds

PDA

Tumor cell i

Figure 16 Schematic representation of: (a) the synthesis of polydopamine via oxidation polymerization, (b) the formation of stimuli-responsive MSN-SS-PDA/DOX particles, and (c) in vivo chemo-photothermal therapy on a tumor. Reprinted with permission from ref. [182].

In case of pulmonary drug delivery, drug transfer with prolonged drug retention in the lung is required to achieve treatment efficacy. The number of cases of respiratory diseases, including lung cancer, asthma, pneumonia, idiopathic pulmonary fibrosis, and chronic obstructive pulmonary disease have increased in recent decades, due to smoking, genetic syndromes, and air pollution [184]. Inhaled drug carriers have the ability to transfer therapeutic drugs and provide sustained release to the target. Their particle size ranges widely from nano to micron sizes, depending on the target deposit site. For example, nanoparticles can diffuse through alveoli, while particles of 1-5 $\mu \mathrm{m}$ are deposited in the deep lungs. In contrast, particles with sizes larger than 10 $\mu \mathrm{m}$ are deposited in the oropharyngeal region [184, 185]. Porous particles are light particles with low density $\left(<0.4 \mathrm{~g} / \mathrm{cm}^{3}\right)$ and suitable hydrodynamic diameters $(1-3 \mu \mathrm{m})$ for improving deep lung deposition. Several biodegradable polymers were used to prepare inhalable porous particles, such as poly(lactic-co-glycolic acid), poly(lactic acid), chitosan, gelatin, alginate, etc $[185,186]$. Figure 17 illustrates inhalable DOX-loaded PLGA porous microparticles with surface-attachment with TRAIL [187]. These particles were fabricated by a W/O/W double emulsion using ammonium bicarbonate as a pore-forming agent, while their surface was modified by strong ionic interaction 
between TRAIL and poly(ethylene-alt-maleic anhydride) (PEMA). The inhalable microparticles showed excellent drug delivery to the lung over a 7-day period by leaching TRAIL and breaking ionic bonds around the particle surface, leading to DOX release.

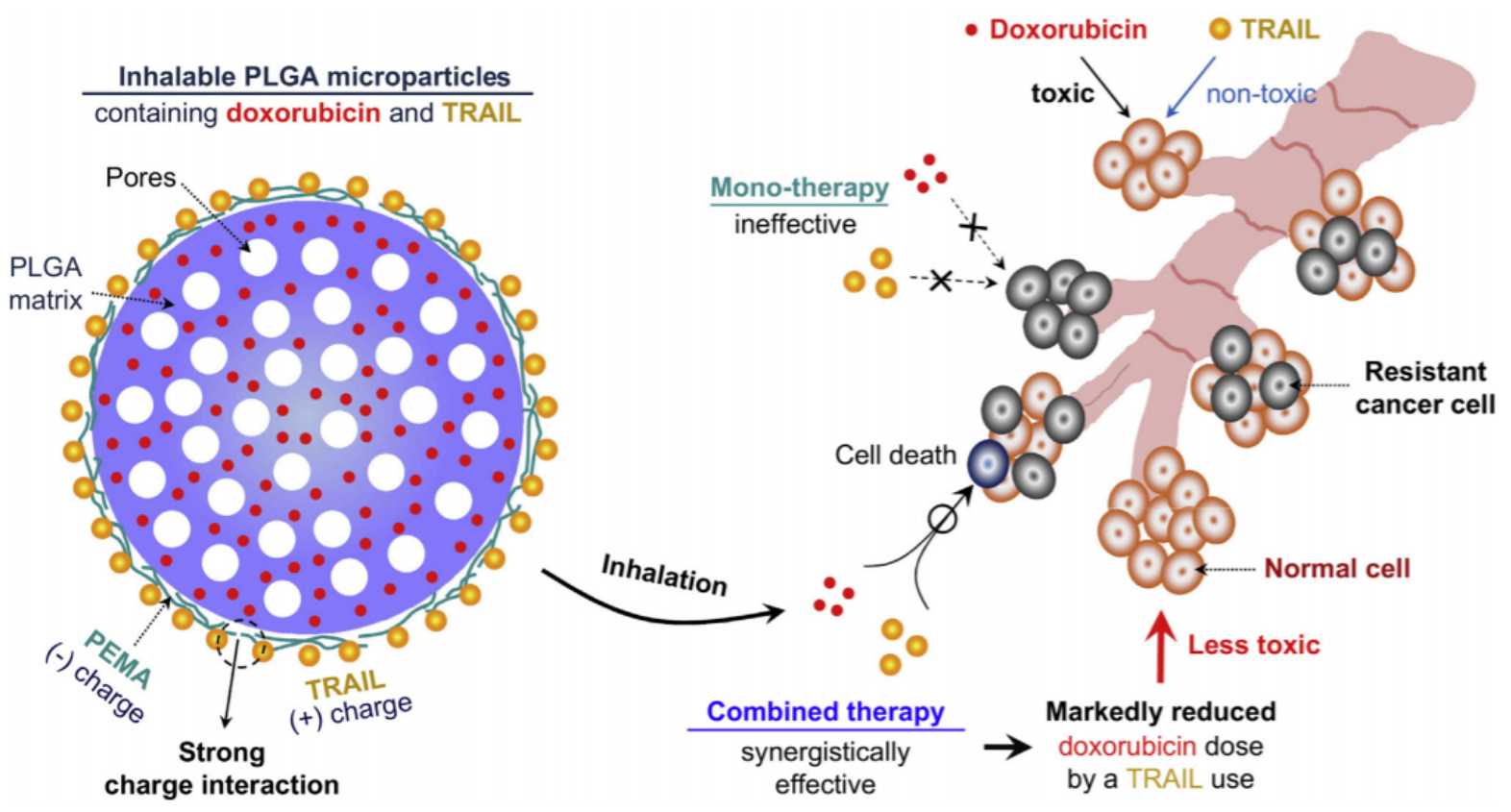

Figure 17 Schematic demonstration of inhalable TRAIL/Dox-loaded PLGA porous microspheres for anti-lung tumor treatment. Reprinted with permission from ref. [187].

Stimuli-responsive porous materials have been used prospectively in the clinical stages of tissue engineering and regenerative medicine. The three dimensional (3D) structures of porous particles serve as mechanical supports and they can transport nutrients or growth factors to injured tissues, for example skin, bone and cartilage, blood vessels, and nerves [188]. The high surface area of the porous structure can induce cell adhesion and regeneration [64]. Almost all types of bone diseases usually display the characteristic of increasing temperature $\left(\sim 2-3^{\circ} \mathrm{C}\right)$, due to inflammation, or decreasing $\mathrm{pH}$ due to osteolytic cancer. Thus, these disorders can be diagnosed by stimuli triggers, such as $\mathrm{pH}$, temperature, redox, and enzymes [189-191]. Gan et al. investigated pH responsive chitosan-functionalized MSN for the dual-delivery of bone morphogenetic protein2 (BMP-2) and dexamethasone (Dex), which are used to induce osteoblast differentiation. Crosslinked chitosan plays a role as a pH-responsive gatekeeper, immobilizing BMP-2 molecules onto the Dex-loaded MSN. In physiological state, BMP-2 was rapidly isolated from the chitosanMSN surface, and bound to its specific cell receptors. However, in endocytosis, decreasing the $\mathrm{pH}$ of the environment stimulated Dex release through the dispersal of chitosan. Dex was then diffused 
into the cytosol, (Figure 18). Finally, an in vivo study showed that osteogenesis was enhanced in the mouse ectopic bone [192].

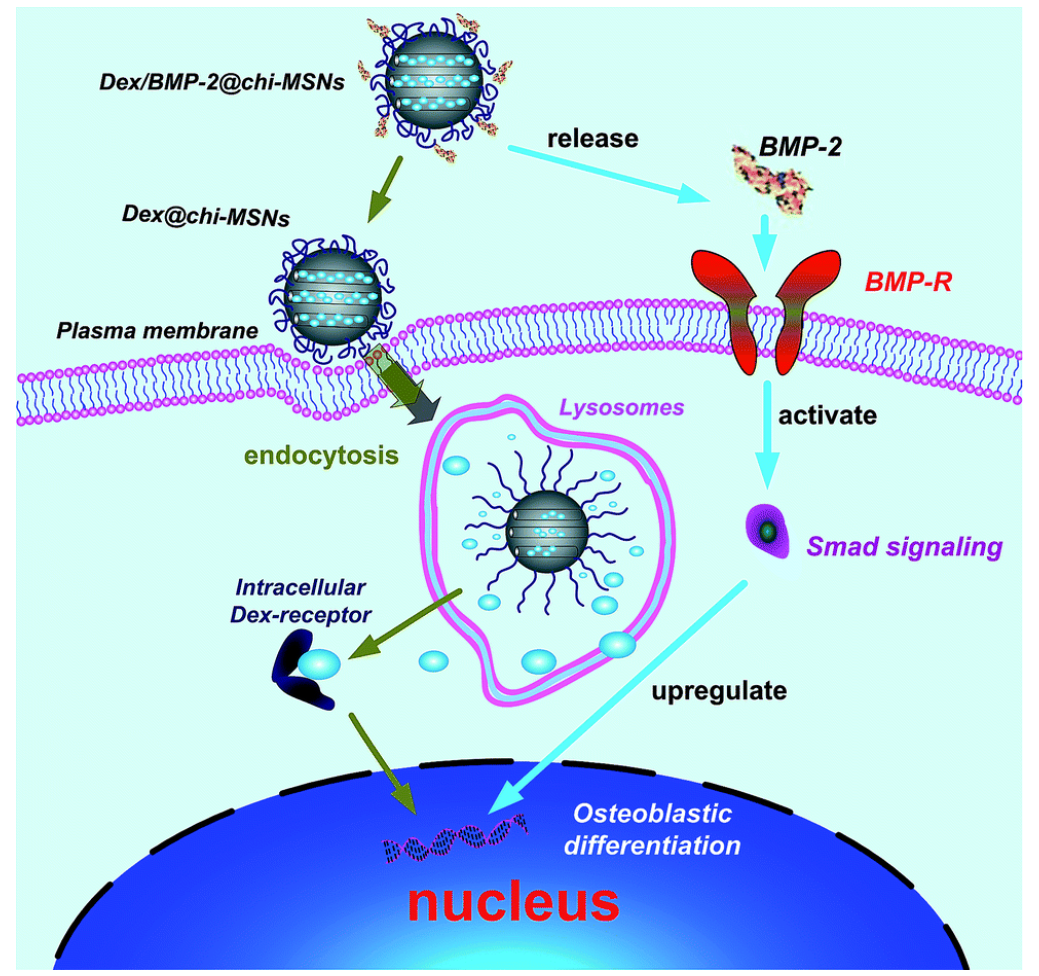

Figure 18 Schematic diagram showing a $\mathrm{pH}$-responsive chitosan-functionalized MSN and the controlled release of BMP-2 and Dex on osteoblast differentiation. Reprinted with permission from ref. [192].

\section{Conclusions}

This review summarizes the research progress on stimuli-responsive porous particles for drug delivery applications. Porous structures can be approached by using pore-forming agents, or by self-forming using chemical synthesis, such as seed polymerization and the double emulsion technique. The controlled size of the particles and their pore size distribution are related to their specific target sites. Porous particles offer enhancements in drug loading capacity, colloidal stability, targeting ability, biological stability, and biodegradability in the human body. Biocompatible porous drug carriers have unique properties of high surface area, large pore volume, and easy-to-modify surfaces, all of which can also improve drug encapsulation efficacy and sustained release. Effective encapsulated drug approaches require increasing the surface area and the surface drug affinity of the carriers. 
The design strategies of smart gates involve their fabrication during or after the particle formation steps. Changes in the environment or external driving forces, such as temperature, $\mathrm{pH}$, redox, light, magnetic field, ultrasonication, and chemical variations induce changes in the conformations of stimuli-responsive polymers. Both exogenous and endogenous stimuligatekeepers display self-regulation in response to stimuli to block premature leakage or allow the release of entrapped drugs. Therefore, the surface modification, functionalization, and precise gate capping position are major challenges to produce the effective smart drug carriers. Stimuliresponsive particles permit further control of kinetic release over time at a specific target location. Several stimuli-capping materials, such as inorganic nanoparticles, macromolecules and polymers play a key role in blocking the outlet pores. A combination of dual or multi stimuli can be employed to obtain sequential or simultaneous responses, depending on the intended behavior inside the body, and the therapeutic approach. The behaviors of multifunctional particles can be monitored directly in real-time, during their controlled drug release or tissue regeneration in a complex in vivo microenvironment. Future efforts should focus on the fabrication of novel smart gating particles, as well as examine their detailed trigger mechanisms. Smart gating particles are promising candidates for application in future drug delivery methods and medical treatments.

\section{Acknowledgments}

$\mathrm{K}$. Thananukul is grateful for the scholarship support she received from The Royal Golden Jubilee (RGJ) Ph.D. program of the National Research Council of Thailand (PHD/0108/2560), and the additional grants from the French Embassy fellowship and the Center of Excellence in Materials and Plasma Technology (CoE M@P Tech), Thammasat University.

\section{Abbreviations list}

BMP-2, bone morphogenetic protein-2

$\mathrm{CD}$, cyclodextrain

Con A, Concanavalin A

CTAB, cetyltrimethylammonium bromide

Dex, dexamethasone

DOX, doxorubicin

FITC-Ins, fluoresein isothiocyanate-labeled insulin

GOx, glucose oxidase

GSH, glutathione

HA, hyaluronic acid

$\mathrm{KCl}$, potassium chloride 
LCST, low critical solution temperature

MNPs, magnetic nanoparticles

MSNs, mesoporous silica nanoparticles

$\mathrm{NH}_{4} \mathrm{HCO}_{3}$, ammonium bicarbonate

NPs, nanoparticles

PBS, phosphate buffered saline

PBA, Phenylboronic acid

PCL, poly(E-caprolactone)

PCM, phase change material

PDA, polydopamine

PDMS, polydimethylsiloxane

PEG, polyethylene glycol

PEG-PPG-PEG, poly(ethylene glycol)-block-poly(propylene glycol)-block-poly(ethylene glycol)

PEMA, poly(ethylene-alt-maleic anhydride)

PGMA, poly(glycidyl methacrylate)

PHEMA, poly(2-hydroxyethylmethacrylate)

PLGA, poly(lactic-co-glycolic acid)

PLA, polylactic acid

PLLA, poly $l$-lactide

PMMA, poly (methyl methacrylate)

PNIPAM, poly( $N$-isopropyl acrylamide)

PTRIM, poly(trimethylol propane trimethacrylate)

PVCL, $\operatorname{poly}(N$-vinylcaprolactam)

SGFLG, succinic acid-glycine-phenylalanine-leucine-glycine

THPMA, 2-tetrahydropyranyl methacrylate

UCST, upper critical solution temperature

\section{References}

[1] F.S. Kodeh, I.M. El-Nahhal, F.H. Abd el-salam, Sol-Gel Encapsulation of Thymol Blue in Presence of Some Surfactants, Chem. Afr., 2 (2019) 67-76.

[2] M.S. Shim, Y.J. Kwon, Stimuli-responsive polymers and nanomaterials for gene delivery and imaging applications, Adv. Drug Delivery Rev., 64 (2012) 1046-1059.

[3] E. Cabane, X. Zhang, K. Langowska, C.G. Palivan, W. Meier, Stimuli-Responsive Polymers and Their Applications in Nanomedicine, Biointerphases, 7 (2012) 9.

[4] W. Gao, J.M. Chan, O.C. Farokhzad, pH-Responsive Nanoparticles for Drug Delivery, Mol. Pharmaceutics, 7 (2010) 1913-1920.

[5] S. Qiao, H. Wang, Temperature-responsive polymers: Synthesis, properties, and biomedical applications, Nano Res., 11 (2018) 5400-5423.

[6] S.F. Medeiros, A.M. Santos, H. Fessi, A. Elaissari, Stimuli-responsive magnetic particles for biomedical applications, Int. J. Pharm., 403 (2011) 139-161. 
[7] M.C. García, 14 - Ionic-strength-responsive polymers for drug delivery applications, in: A.S.H. Makhlouf, N.Y. Abu-Thabit (Eds.) Stimuli Responsive Polymeric Nanocarriers for Drug Delivery Applications, Woodhead Publishing2019, pp. 393-409.

[8] Y. Hao, J. Meng, S. Wang, Photo-responsive polymer materials for biological applications, Chin. Chem. Lett., 28 (2017) 2085-2091.

[9] Y.L. Colson, M.W. Grinstaff, Biologically Responsive Polymeric Nanoparticles for Drug Delivery, Adv. Mater., 24 (2012) 3878-3886.

[10] Z.-Q. Cao, G.-J. Wang, Multi-Stimuli-Responsive Polymer Materials: Particles, Films, and Bulk Gels, Chem. Rec., 16 (2016) 1398-1435.

[11] S. Hajebi, N. Rabiee, M. Bagherzadeh, S. Ahmadi, M. Rabiee, H. Roghani-Mamaqani, M. Tahriri, L. Tayebi, M.R. Hamblin, Stimulus-responsive polymeric nanogels as smart drug delivery systems, Acta Biomater., 92 (2019) 1-18.

[12] G.G. Abdo, M.M. Zagho, A. Khalil, Recent advances in stimuli-responsive drug release and targeting concepts using mesoporous silica nanoparticles, Emergent Mater., 3 (2020) 407-425.

[13] P. Poddar, P. Maity, S. Maiti, S. Sahoo, S. Dhara, D. Dhara, Synthesis of a new tripleresponsive biocompatible block copolymer: Self-assembled nanoparticles as potent anticancer drug delivery vehicle, React. Funct. Polym., 154 (2020) 104679.

[14] H. Wu, J. Dong, X. Zhan, H. Yang, Y. Zhao, S. Zhu, G. Wang, Triple stimuli-responsive crosslinked polymeric nanoparticles for controlled release, RSC Adv., 4 (2014) 35757-35761.

[15] I.M. Martins, M.F. Barreiro, M. Coelho, A.E. Rodrigues, Microencapsulation of essential oils with biodegradable polymeric carriers for cosmetic applications, Chem. Eng. J., 245 (2014) 191200.

[16] M. Li, O. Rouaud, D. Poncelet, Microencapsulation by solvent evaporation: State of the art for process engineering approaches, Int. J. Pharm., 363 (2008) 26-39.

[17] W. Yin, M.Z. Yates, Encapsulation and sustained release from biodegradable microcapsules made by emulsification/freeze drying and spray/freeze drying, J. Colloid Interface Sci., 336 (2009) 155-161.

[18] R. Dubey, T.C. Shami, K.U. Rao, Microencapsulation Technology and Applications, Def. Sci. J., 59 (2009) 82-95.

[19] M. Iqbal, N. Zafar, H. Fessi, A. Elaissari, Double emulsion solvent evaporation techniques used for drug encapsulation, Int. J. Pharm., 496 (2015) 173-190.

[20] A.P. Blum, J.K. Kammeyer, A.M. Rush, C.E. Callmann, M.E. Hahn, N.C. Gianneschi, Stimuli-Responsive Nanomaterials for Biomedical Applications, J. Am. Chem. Soc., 137 (2015) 2140-2154.

[21] S. Jiang, A. Van Dyk, A. Maurice, J. Bohling, D. Fasano, S. Brownell, Design colloidal particle morphology and self-assembly for coating applications, Chem. Soc. Rev., 46 (2017) 37923807.

[22] S. Kharel, W.L. Lee, X.Y. Lee, S.C.J. Loo, Osmogen-Mediated One-Step Technique of Fabricating Hollow Microparticles for Encapsulation and Delivery of Bioactive Molecules, Macromol. Biosci., 17 (2017) 1600328.

[23] R. Ghosh Chaudhuri, S. Paria, Core/Shell Nanoparticles: Classes, Properties, Synthesis Mechanisms, Characterization, and Applications, Chem. Rev., 112 (2012) 2373-2433.

[24] H. Kim, B.R. Kim, Y.J. Shin, S. Cho, J. Lee, Controlled formation of polylysinized inner pores in injectable microspheres of low molecular weight poly(lactide-co-glycolide) designed for efficient loading of therapeutic cells, Artif. Cells, Nanomed., Biotechnol., 46 (2018) S233-S246. 
[25] R. Narayan, U. Nayak, A. Raichur, S. Garg, Mesoporous Silica Nanoparticles: A Comprehensive Review on Synthesis and Recent Advances, Pharmaceutics, 10 (2018) 118.

[26] I.M. El-Nahhal, F.S. Kodeh, J.K. Salem, T. Hammad, S. Kuhn, R. Hempelmann, S. Al Bhaisi, Silica, Mesoporous Silica and Its Thiol Functionalized Silica Coated $\mathrm{MgO}$ and $\mathrm{Mg}(\mathrm{OH}) 2$ Materials, Chem. Afr., 2 (2019) 267-276.

[27] Z. Liu, W. Wang, R. Xie, X.-J. Ju, L.-Y. Chu, Stimuli-responsive smart gating membranes, Chem. Soc. Rev., 45 (2016) 460-475.

[28] M.T. Gokmen, F.E. Du Prez, Porous polymer particles - A comprehensive guide to synthesis, characterization, functionalization and applications, Prog. Polym. Sci., 37 (2012) 365-405.

[29] X.-D. Shi, P.-J. Sun, Z.-H. Gan, Preparation of Porous Polylactide Microspheres and Their Application in Tissue Engineering, Chin. J. Polym. Sci., 36 (2018) 712-719.

[30] Q. Qian, X. Huang, X. Zhang, Z. Xie, Y. Wang, One-step Preparation of Macroporous Polymer Particles with Multiple Interconnected Chambers: A Candidate for Trapping Biomacromolecules, Angew. Chem. Int. Ed., 52 (2013) 10625-10629.

[31] X.-M. Na, F. Gao, L.-Y. Zhang, Z.-G. Su, G.-H. Ma, Biodegradable Microcapsules Prepared by Self-Healing of Porous Microspheres, ACS Macro Lett., 1 (2012) 697-700.

[32] Q. Zhang, K. Tan, Z. Ye, Y. Zhang, W. Tan, M. Lang, Preparation of open porous polycaprolactone microspheres and their applications as effective cell carriers in hydrogel system, Mater. Sci. Eng. C, 32 (2012) 2589-2595.

[33] N. Zafar, A. Bitar, J.P. Valour, H. Fessi, A. Elaissari, Elaboration of ammonio methacrylate copolymer based spongy cationic particles via double emulsion solvent evaporation process, Mater. Sci. Eng. C, 61 (2016) 85-96.

[34] D. Grande, G. Rohman, Oligoester-Derivatized (Semi-)Interpenetrating Polymer Networks as Nanostructured Precursors to Porous Materials with Tunable Porosity, Chem. Afr., 2 (2019) 253-265.

[35] L. Sun, S. Zhou, W. Wang, X. Li, J. Wang, J. Weng, Preparation and characterization of porous biodegradable microspheres used for controlled protein delivery, Colloids Surf., A, 345 (2009) 173-181.

[36] S.A. Ashter, Overview of Biodegradable Polymers, in: S.A. Ashter (Ed.) Introduction to Bioplastics Engineering, William Andrew Publishing, Oxford, 2016, pp. 19-30.

[37] I. Tokarev, S. Minko, Stimuli-Responsive Porous Hydrogels at Interfaces for Molecular Filtration, Separation, Controlled Release, and Gating in Capsules and Membranes, Adv. Mater., 22 (2010) 3446-3462.

[38] X. Fu, L. Hosta-Rigau, R. Chandrawati, J. Cui, Multi-Stimuli-Responsive Polymer Particles, Films, and Hydrogels for Drug Delivery, Chem, 4 (2018) 2084-2107.

[39] A. Mehmood, H. Ghafar, S. Yaqoob, U.F. Gohar, B. Ahmad, Mesoporous Silica Nanoparticles: A Review, J. Dev. Drugs, 6 (2017) 1000174.

[40] M. Zhou, L. Shen, X. Lin, Y. Hong, Y. Feng, Design and pharmaceutical applications of porous particles, RSC Adv., 7 (2017) 39490-39501.

[41] P. Yang, S. Gai, J. Lin, Functionalized mesoporous silica materials for controlled drug delivery, Chem. Soc. Rev., 41 (2012) 3679-3698.

[42] J. Florek, R. Caillard, F. Kleitz, Evaluation of mesoporous silica nanoparticles for oral drug delivery - current status and perspective of MSNs drug carriers, Nanoscale, 9 (2017) 15252-15277. [43] S. Ding, C.A. Serra, T.F. Vandamme, W. Yu, N. Anton, Double emulsions prepared by twostep emulsification: History, state-of-the-art and perspective, J. Controlled Release, 295 (2019) 31-49. 
[44] M. Yildirim, G. Sumnu, S. Sahin, The effects of emulsifier type, phase ratio, and homogenization methods on stability of the double emulsion, J. Dispersion Sci. Technol., 38 (2017) 807-814.

[45] Y. Xie, D. Kocaefe, C. Chen, Y. Kocaefe, Review of Research on Template Methods in Preparation of Nanomaterials, J. Nanomater., 2016 (2016) 2302595.

[46] Y. Liu, J. Goebl, Y. Yin, Templated synthesis of nanostructured materials, Chem. Soc. Rev., 42 (2013) 2610-2653.

[47] A.B.D. Nandiyanto, T. Ogi, W.-N. Wang, L. Gradon, K. Okuyama, Template-assisted spraydrying method for the fabrication of porous particles with tunable structures, Adv. Powder Technol., 30 (2019) 2908-2924.

[48] Y. Cai, Y. Chen, X. Hong, Z. Liu, W. Yuan, Porous microsphere and its applications, Int. J. Nanomed., 8 (2013) 1111-1120.

[49] B. Amoyav, O. Benny, Microfluidic Based Fabrication and Characterization of Highly Porous Polymeric Microspheres, Polymers, 11 (2019) 419.

[50] B. Wang, P. Prinsen, H. Wang, Z. Bai, H. Wang, R. Luque, J. Xuan, Macroporous materials: microfluidic fabrication, functionalization and applications, Chem. Soc. Rev., 46 (2017) 855-914. [51] W. Li, L. Zhang, X. Ge, B. Xu, W. Zhang, L. Qu, C.-H. Choi, J. Xu, A. Zhang, H. Lee, D.A. Weitz, Microfluidic fabrication of microparticles for biomedical applications, Chem. Soc. Rev., 47 (2018) 5646-5683.

[52] Z. Derui, Q. Long, Y. Xu, J. Xing, Evaluating Nanoparticles in Preclinical Research Using Microfluidic Systems, Micromachines, 10 (2019) 414.

[53] A. Sosnik, K.P. Seremeta, Advantages and challenges of the spray-drying technology for the production of pure drug particles and drug-loaded polymeric carriers, Adv. Colloid Interface Sci., 223 (2015) 40-54.

[54] J. Yao, L. Kuang Lim, J. Xie, J. Hua, C.-H. Wang, Characterization of electrospraying process for polymeric particle fabrication, J. Aerosol Sci., 39 (2008) 987-1002.

[55] A.B.D. Nandiyanto, K. Okuyama, Progress in developing spray-drying methods for the production of controlled morphology particles: From the nanometer to submicrometer size ranges, Adv. Powder Technol., 22 (2011) 1-19.

[56] R. Vehring, Pharmaceutical Particle Engineering via Spray Drying, Pharm. Res., 25 (2008) 999-1022.

[57] W. Stöber, A. Fink, E. Bohn, Controlled growth of monodisperse silica spheres in the micron size range, J. Colloid Interface Sci., 26 (1968) 62-69.

[58] M. Vallet-Regi, A. Rámila, R.P. del Real, J. Pérez-Pariente, A New Property of MCM-41: Drug Delivery System, Chem. Mater., 13 (2001) 308-311.

[59] A. Bakhshian Nik, H. Zare, S. Razavi, H. Mohammadi, P. Torab Ahmadi, N. Yazdani, M. Bayandori, N. Rabiee, J. Izadi Mobarakeh, Smart drug delivery: Capping strategies for mesoporous silica nanoparticles, Microporous Mesoporous Mater., 299 (2020) 110115.

[60] S.-H. Wu, C.-Y. Mou, H.-P. Lin, Synthesis of mesoporous silica nanoparticles, Chem. Soc. Rev., 42 (2013) 3862-3875.

[61] L. Han, Y. Zhou, T. He, G. Song, F. Wu, F. Jiang, J. Hu, One-pot morphology-controlled synthesis of various shaped mesoporous silica nanoparticles, J. Mater. Sci., 48 (2013) 5718-5726. [62] F. Babonneau, L. Camus, N. Steunou, A. Ramila, M. Vallet-Regi, Encapsulation of ibuprofen in mesoporous silica: Solid state NMR characterization, MRS Proceedings, 775 (2003) 77-82. 
[63] S. Kwon, R.K. Singh, R.A. Perez, E.A. Abou Neel, H.-W. Kim, W. Chrzanowski, Silicabased mesoporous nanoparticles for controlled drug delivery, J. Tissue Eng., 4 (2013) 2041731413503357.

[64] J.-B. Fan, C. Huang, L. Jiang, S. Wang, Nanoporous microspheres: from controllable synthesis to healthcare applications, J. Mater. Chem. B, 1 (2013) 2222-2235.

[65] M. Iqbal, J.-P. Valour, H. Fessi, A. Elaissari, Preparation of biodegradable PCL particles via double emulsion evaporation method using ultrasound technique, Colloid Polym. Sci., 293 (2015) 861-873.

[66] N. Zafar, G. Agusti, H. Fessi, A. Elaissari, Elaboration of sponge-like biodegradable cationic particles via double-emulsion solvent evaporation, J. Dispersion Sci. Technol., 38 (2017) 577-583. [67] R. Muñoz-Espí, Y. Mastai, S. Gross, K. Landfester, Colloidal systems for crystallization processes from liquid phase, CrystEngComm, 15 (2013) 2175-2191.

[68] M.N. Gorsd, M.N. Blanco, L.R. Pizzio, Synthesis of Polystyrene Microspheres to be Used as Template in the Preparation of Hollow Spherical Materials: Study of the Operative Variables, Procedia Mater. Sci., 1 (2012) 432-438.

[69] H. Zhang, H. Xu, M. Wu, Y. Zhong, D. Wang, Z. Jiao, A soft-hard template approach towards hollow mesoporous silica nanoparticles with rough surfaces for controlled drug delivery and protein adsorption, J. Mater. Chem. B, 3 (2015) 6480-6489.

[70] G. Kawamura, H. Muto, A. Matsuda, Hard template synthesis of metal nanowires, Front. Chem., 2 (2014).

[71] Y. Wang, C. He, A. Brouzgou, Y. Liang, R. Fu, D. Wu, P. Tsiakaras, S. Song, A facile softtemplate synthesis of ordered mesoporous carbon/tungsten carbide composites with high surface area for methanol electrooxidation, J. Power Sources, 200 (2012) 8-13.

[72] H. Tian, L. Zhixing, F. Xu, J. Zheng, X. Zhuang, Y. Mai, X. Feng, Quantitative Control of Pore Size of Mesoporous Carbon Nanospheres through the Self-Assembly of Diblock Copolymer Micelles in Solution, Small, 12 (2016) 3155-3163.

[73] S. Cao, G. Gody, W. Zhao, S. Perrier, X. Peng, C. Ducati, D. Zhao, A.K. Cheetham, Hierarchical bicontinuous porosity in metal-organic frameworks templated from functional block co-oligomer micelles, Chem. Sci., 4 (2013) 3573-3577.

[74] F.R. Mansour, S. Waheed, B. Paull, F. Maya, Porogens and porogen selection in the preparation of porous polymer monoliths, J. Sep. Sci., 43 (2020) 56-69.

[75] H. Cong, B. Yu, L. Gao, B. Yang, F. Gao, H. Zhang, Y. Liu, Preparation of morphologycontrollable PGMA-DVB microspheres by introducing Span 80 into seed emulsion polymerization, RSC Adv., 8 (2018) 2593-2598.

[76] F. Ungaro, C. Giovino, C. Coletta, R. Sorrentino, A. Miro, F. Quaglia, Engineering gasfoamed large porous particles for efficient local delivery of macromolecules to the lung, Eur. J. Pharm. Sci., 41 (2010) 60-70.

[77] C.K. Sahoo, N.K. Sahoo, S.R.M. Rao, M. Sudhakar, K. Satyanarayana, A review on controlled porosity osmotic pump tablets and its evaluation, Bull. Fac. Pharm. (Cairo Univ.), 53 (2015) 195-205.

[78] S.L. Shamblin, Controlled Release Using Bilayer Osmotic Tablet Technology: Reducing Theory to Practice, in: H. Wen, K. Park (Eds.) Oral Controlled Release Formulation Design and Drug Delivery, John Wiley \& Sons, Inc.2010, pp. 129-153.

[79] J. Lee, Y.J. Oh, S.K. Lee, K.Y. Lee, Facile control of porous structures of polymer microspheres using an osmotic agent for pulmonary delivery, J. Controlled Release, 146 (2010) 61-67. 
[80] B. Yu, T. Xue, L. Pang, X. Zhang, Y. Shen, H. Cong, The Effect of Different Porogens on Porous PMMA Microspheres by Seed Swelling Polymerization and Its Application in HighPerformance Liquid Chromatography, Materials (Basel), 11 (2018) 705.

[81] H.Y. Son, D.J. Lee, J.B. Lee, C.H. Park, M. Seo, J. Jang, S.J. Kim, M.S. Yoon, Y.S. Nam, In situ functionalization of highly porous polymer microspheres with silver nanoparticles via bioinspired chemistry, RSC Adv., 4 (2014) 55604-55609.

[82] H.K. Kim, H.J. Chung, T.G. Park, Biodegradable polymeric microspheres with "open/closed" pores for sustained release of human growth hormone, J. Controlled Release, 112 (2006) 167-174. [83] O. Qutachi, J.R. Vetsch, D. Gill, H. Cox, D.J. Scurr, S. Hofmann, R. Müller, R.A. Quirk, K.M. Shakesheff, C.V. Rahman, Injectable and porous PLGA microspheres that form highly porous scaffolds at body temperature, Acta Biomater., 10 (2014) 5090-5098.

[84] A. Mittal, P. Negi, K. Garkhal, S. Verma, N. Kumar, Integration of porosity and biofunctionalization to form a 3D scaffold: cell culture studies and in vitro degradation, Biomed. Mater., 5 (2010) 045001.

[85] A. Chen, N. Tang, S. Wang, Y. Kang, H. Song, Insulin-loaded poly-l-lactide porous microspheres prepared in supercritical CO2 for pulmonary drug delivery, J. Supercrit. Fluids, 101 (2015) 117-123.

[86] A. Chvatal, R. Ambrus, P. Party, G. Katona, J.-L. O., S.-R. P., E. Fattal, N. Tsapis, Formulation and comparison of spray dried non-porous and large porous particles containing meloxicam for pulmonary drug delivery, Int. J. Pharm., 559 (2019) 68-75.

[87] P. Yuan, X. Qiu, R. Jin, Y. Bai, S. Liu, X. Chen, One-pot preparation of polymer microspheres with different porous structures to sequentially release bio-molecules for cutaneous regeneration, Biomater. Sci., 6 (2018) 820-826.

[88] W.-Q. Zhou, T.-Y. Gu, Z.-G. Su, G.-H. Ma, Synthesis of macroporous poly(glycidyl methacrylate) microspheres by surfactant reverse micelles swelling method, Eur. Polym. J., 43 (2007) 4493-4502.

[89] C.D. Wood, A.I. Cooper, Synthesis of Macroporous Polymer Beads by Suspension Polymerization Using Supercritical Carbon Dioxide as a Pressure-Adjustable Porogen, Macromolecules, 34 (2001) 5-8.

[90] M. Nasr, G.A.S. Awad, S. Mansour, I. Taha, A.A. Shamy, N.D. Mortada, Different modalities of $\mathrm{NaCl}$ osmogen in biodegradable microspheres for bone deposition of risedronate sodium by alveolar targeting, Eur. J. Pharm. Biopharm., 79 (2011) 601-611.

[91] T. Uchida, K. Yoshida, S. Goto, Preparation and characterization of polylactic acid microspheres containing water-soluble dyes using a novel $\mathrm{w} / \mathrm{o} / \mathrm{w}$ emulsion solvent evaporation method, J. Microencapsulation, 13 (1996) 219-228.

[92] K. Chon, J. Moon, S. Kim, S.-D. Kim, J. Cho, Bio-particle separation using microfluidic porous plug for environmental monitoring, Desalination, 202 (2007) 215-223.

[93] K. Jiang, A. Sposito, J. Liu, S.R. Raghavan, D.L. DeVoe, Microfluidic synthesis of macroporous polymer immunobeads, Polymer, 53 (2012) 5469-5475.

[94] F. Iskandar, A.B.D. Nandiyanto, W. Widiyastuti, L.S. Young, K. Okuyama, L. Gradon, Production of morphology-controllable porous hyaluronic acid particles using a spray-drying method, Acta Biomater., 5 (2009) 1027-1034.

[95] T. Peng, X. Zhang, Y. Huang, Z. Zhao, Q. Liao, J. Xu, Z. Huang, J. Zhang, C.-y. Wu, X. Pan, C. $\mathrm{Wu}$, Nanoporous mannitol carrier prepared by non-organic solvent spray drying technique to enhance the aerosolization performance for dry powder inhalation, Sci. Rep., 7 (2017) 46517. 
[96] M. Tarhini, J. Vega-Chacón, M. Jafelicci, N. Zine, A. Errachid, H. Fessi, A. Elaissari, Structured Magnetic Core/Silica Internal Shell Layer and Protein Out Layer Shell (BSA@SiO2@SME): Preparation and Characterization, Chem. Afr., 3 (2020) 127-134.

[97] J. Vega-Chacón, M. Tarhini, N. Lebaz, M. Jafelicci, N. Zine, A. Errachid, A. Elaissari, Protein-Silica Hybrid Submicron Particles: Preparation and Characterization, Chem. Afr., (2020). [98] D.M. Ford, E.D. Glandt, Steric hindrance at the entrances to small pores, J. Membr. Sci., 107 (1995) 47-57.

[99] M. Yang, L.-Y. Chu, H.-D. Wang, R. Xie, H. Song, C.H. Niu, A Thermoresponsive Membrane for Chiral Resolution, Adv. Funct. Mater., 18 (2008) 652-663.

[100] S. Chen, F. Gao, Q. Wang, Z. Su, G. Ma, Double emulsion-templated microspheres with flow-through pores at micrometer scale, Colloid Polym. Sci., 291 (2013) 117-126.

[101] J. Li, S. Shen, F. Kong, T. Jiang, C. Tang, C. Yin, Effects of pore size on in vitro and in vivo anticancer efficacies of mesoporous silica nanoparticles, RSC Adv., 8 (2018) 24633-24640.

[102] A. Sharma, K. Vaghasiya, R.K. Verma, Inhalable microspheres with hierarchical pore size for tuning the release of biotherapeutics in lungs, Microporous Mesoporous Mater., 235 (2016) 195-203.

[103] G. Ahuja, K. Pathak, Porous carriers for controlled/modulated drug delivery, Indian J. Pharm. Sci., 71 (2009) 599-607.

[104] S.E. Bae, J.S. Son, K. Park, D.K. Han, Fabrication of covered porous PLGA microspheres using hydrogen peroxide for controlled drug delivery and regenerative medicine, J. Controlled Release, 133 (2009) 37-43.

[105] M. Gupta, A. Aina, Y. Boukari, S. Doughty, A. Morris, N. Billa, Effect of volume of porogens on the porosity of PLGA scaffolds in $\mathrm{pH}$-controlled environment, Pharm. Dev. Technol., 23 (2018) 207-210.

[106] T.K. Kim, J.J. Yoon, D.S. Lee, T.G. Park, Gas foamed open porous biodegradable polymeric microspheres, Biomaterials, 27 (2006) 152-159.

[107] S. Kim, H. Sah, Merits of sponge-like PLGA microspheres as long-acting injectables of hydrophobic drug, J. Biomater. Sci., Polym. Ed., 30 (2019) 1725-1743.

[108] M.R. Kim, S. Lee, J.-K. Park, K.Y. Cho, Golf ball-shaped PLGA microparticles with internal pores fabricated by simple O/W emulsion, Chem. Commun., 46 (2010) 7433-7435.

[109] Y. Song, J.-B. Fan, X. Li, X. Liang, S. Wang, pH-Regulated Heterostructure Porous Particles Enable Similarly Sized Protein Separation, Adv. Mater., 31 (2019) 1900391.

[110] L. Qiao, L. Zhao, C. Liang, K. Du, The construction of porous chitosan microspheres with high specific surface area by using agarose as the pore-forming agent and further functionalized application in bioseparation, J. Mater. Chem. B, 7 (2019) 5510-5519.

[111] Y. Wang, Y. Shan, K.Z. Chen, L. Gao, Mesoporous Silica Nanoparticles with Controllable Pore Size: Preparation and Drug Release, Adv. Mater. Res., 774-776 (2013) 536-539.

[112] Z. Li, J.C. Barnes, A. Bosoy, J.F. Stoddart, J.I. Zink, Mesoporous silica nanoparticles in biomedical applications, Chem. Soc. Rev., 41 (2012) 2590-2605.

[113] Y. Yan, M. Björnmalm, F. Caruso, Assembly of Layer-by-Layer Particles and Their Interactions with Biological Systems, Chem. Mater., 26 (2014) 452-460.

[114] A. Raza, T. Rasheed, F. Nabeel, U. Hayat, M. Bilal, H.M.N. Iqbal, Endogenous and Exogenous Stimuli-Responsive Drug Delivery Systems for Programmed Site-Specific Release, Molecules, 24 (2019) 1117.

[115] F. Li, Y. Qin, J. Lee, H. Liao, N. Wang, T.P. Davis, R. Qiao, D. Ling, Stimuli-responsive nano-assemblies for remotely controlled drug delivery, J. Controlled Release, 322 (2020) 566-592. 
[116] R.P. Johnson, N.K. Preman, 8 - Responsive block copolymers for drug delivery applications. Part 2: Exogenous stimuli-responsive drug-release systems, in: A.S.H. Makhlouf, N.Y. AbuThabit (Eds.) Stimuli Responsive Polymeric Nanocarriers for Drug Delivery Applications, Woodhead Publishing2018, pp. 221-246.

[117] H. Chen, D. Liu, Z. Guo, Endogenous Stimuli-responsive Nanocarriers for Drug Delivery, Chem. Lett., 45 (2016) 242-249.

[118] M. Ghasemlou, F. Daver, E.P. Ivanova, J.-W. Rhim, B. Adhikari, Switchable Dual-Function and Bioresponsive Materials to Control Bacterial Infections, ACS Appl. Mater. Interfaces, 11 (2019) 22897-22914.

[119] S.A. Jadhav, D. Scalarone, Thermoresponsive Polymer Grafted Porous Silicas as Smart Nanocarriers, Aust. J. Chem., 71 (2018) 477-481.

[120] S.A. Abouelmagd, N.H.A. Ellah, B.N.A.E. Hamid, 3 - Temperature and pH dual-stimuli responsive polymeric carriers for drug delivery, in: A.S.H. Makhlouf, N.Y. Abu-Thabit (Eds.) Stimuli Responsive Polymeric Nanocarriers for Drug Delivery Applications, Woodhead Publishing2019, pp. 87-109.

[121] M. Karimi, P. Sahandi Zangabad, A. Ghasemi, M. Amiri, M. Bahrami, H. Malekzad, H. Ghahramanzadeh Asl, Z. Mahdieh, M. Bozorgomid, A. Ghasemi, M.R. Rahmani Taji Boyuk, M.R. Hamblin, Temperature-Responsive Smart Nanocarriers for Delivery Of Therapeutic Agents: Applications and Recent Advances, ACS Appl. Mater. Interfaces, 8 (2016) 21107-21133.

[122] E. Guisasola, A. Baeza, M. Talelli, D. Arcos, M. Vallet-Regí, Design of thermoresponsive polymeric gates with opposite controlled release behaviors, RSC Adv., 6 (2016) 42510-42516.

[123] A.J. Sushilkumar, D.M. Scalarone, V.G. Brunella, E. Ugazio, S. Sapino, G. Berlier, Thermoresponsive copolymer-grafted SBA-15 porous silica particles for temperature-triggered topical delivery systems, eXPRESS Polym. Lett., 11 (2017) 96-105.

[124] Y. Song, Y. Li, Q. Xu, Z. Liu, Mesoporous silica nanoparticles for stimuli-responsive controlled drug delivery: Advances, challenges, and outlook, Int. J. Nanomed., 12 (2016) 87-110. [125] Q. Yuan, Y. Zhang, T. Chen, D. Lu, Z. Zhao, X. Zhang, Z. Li, C.-H. Yan, W. Tan, PhotonManipulated Drug Release from a Mesoporous Nanocontainer Controlled by AzobenzeneModified Nucleic Acid, ACS Nano, 6 (2012) 6337-6344.

[126] X. Mei, S. Yang, D. Chen, N. Li, H. Li, Q. Xu, J. Ge, J. Lu, Light-triggered reversible assemblies of azobenzene-containing amphiphilic copolymer with $\beta$-cyclodextrin-modified hollow mesoporous silica nanoparticles for controlled drug release, Chem. Commun., 48 (2012) 10010-10012.

[127] D. Wang, W. Zhao, Q. Wei, C. Zhao, Y. Zheng, Photoswitchable Azobenzene/Cyclodextrin Host-Guest Complexes: From UV- to Visible/Near-IR-Light-Responsive Systems, ChemPhotoChem, 2 (2018) 403-415.

[128] D. Liu, F. Yang, F. Xiong, N. Gu, The Smart Drug Delivery System and Its Clinical Potential, Theranostics, 6 (2016) 1306-1323.

[129] A. Baykal, A. Bozkurt, R. Jeremy, S.M.M. Asiri, M.K. Lima-Tenório, C. Kaewsaneha, A. Elaissari, 6 - Multistimuli-responsive magnetic assemblies, in: A.S.H. Makhlouf, N.Y. Abu-Thabit (Eds.) Stimuli Responsive Polymeric Nanocarriers for Drug Delivery Applications, Woodhead Publishing2019, pp. 155-193.

[130] C. Yang, W. Guo, L. Cui, N. An, T. Zhang, H. Lin, F. Qu, pH-Responsive Magnetic CoreShell Nanocomposites for Drug Delivery, Langmuir, 30 (2014) 9819-9827. 
[131] A. Baeza, E. Guisasola, E. Ruiz-Hernández, M. Vallet-Regí, Magnetically Triggered Multidrug Release by Hybrid Mesoporous Silica Nanoparticles, Chem. Mater., 24 (2012) 517524.

[132] A.-Z. Zardad, Y.E. Choonara, L.C. Du Toit, P. Kumar, M. Mabrouk, P.P.D. Kondiah, V. Pillay, A Review of Thermo- and Ultrasound-Responsive Polymeric Systems for Delivery of Chemotherapeutic Agents, Polymers, 8 (2016) 359.

[133] J.L. Paris, M.V. Cabañas, M. Manzano, M. Vallet-Regí, Polymer-Grafted Mesoporous Silica Nanoparticles as Ultrasound-Responsive Drug Carriers, ACS Nano, 9 (2015) 11023-11033.

[134] N. Deirram, C. Zhang, S.S. Kermaniyan, A.P.R. Johnston, G.K. Such, pH-Responsive Polymer Nanoparticles for Drug Delivery, Macromol. Rapid Commun., 40 (2019) 1800917.

[135] G. Kocak, C. Tuncer, V. Bütün, pH-Responsive polymers, Polym. Chem., 8 (2017) 144-176. [136] Z. Lin, J. Li, H. He, H. Kuang, X. Chen, Z. Xie, X. Jing, Y. Huang, Acetalated-dextran as valves of mesoporous silica particles for $\mathrm{pH}$ responsive intracellular drug delivery, RSC Adv., 5 (2015) 9546-9555.

[137] A. Raza, U. Hayat, T. Rasheed, M. Bilal, H.M.N. Iqbal, Redox-responsive nano-carriers as tumor-targeted drug delivery systems, Eur. J. Med. Chem., 157 (2018) 705-715.

[138] Z. Yi, H.I. Hussain, C. Feng, D. Sun, F. She, J.E. Rookes, D.M. Cahill, L. Kong, Functionalized Mesoporous Silica Nanoparticles with Redox-Responsive Short-Chain Gatekeepers for Agrochemical Delivery, ACS Appl. Mater. Interfaces, 7 (2015) 9937-9946.

[139] Y. Wang, N. Han, Q. Zhao, L. Bai, J. Li, T. Jiang, S. Wang, Redox-responsive mesoporous silica as carriers for controlled drug delivery: A comparative study based on silica and PEG gatekeepers, Eur. J. Pharm. Sci., 72 (2015) 12-20.

[140] J. Lee, H. Lee, J. Kim, C. Kim, Stimuli-Responsive Peptide Gatekeepers for Smart Nanocarriers, Macromol. Res., 28 (2020) 185-195.

[141] T. Zhang, S. Huang, H. Lin, N. An, R. Tong, Y. Chen, Y. Wang, F. Qu, Enzyme and pHresponsive nanovehicles for intracellular drug release and photodynamic therapy, New J. Chem., 41 (2017) 2468-2478.

[142] R. Liao, P. Lv, Q. Wang, J. Zheng, B. Feng, B. Yang, Cyclodextrin-based biological stimuliresponsive carriers for smart and precision medicine, Biomater. Sci., 5 (2017) 1736-1745.

[143] Y. Xiao, T. Wang, Y. Cao, X. Wang, Y. Zhang, Y. Liu, Q. Huo, Enzyme and voltage stimuliresponsive controlled release system based on $\beta$-cyclodextrin-capped mesoporous silica nanoparticles, Dalton Trans., 44 (2015) 4355-4361.

[144] C. Park, H. Kim, S. Kim, C. Kim, Enzyme Responsive Nanocontainers with Cyclodextrin Gatekeepers and Synergistic Effects in Release of Guests, J. Am. Chem. Soc., 131 (2009) 1661416615.

[145] P. Eskandari, B. Bigdeli, M. Porgham Daryasari, H. Baharifar, B. Bazri, M. Shourian, A. Amani, A. Sadighi, B. Goliaei, M. Khoobi, A.A. Saboury, Gold-capped mesoporous silica nanoparticles as an excellent enzyme-responsive nanocarrier for controlled doxorubicin delivery, J. Drug Targeting, 27 (2019) 1084-1093.

[146] D. Shen, H. Yu, L. Wang, A. Khan, F. Haq, X. Chen, Q. Huang, L. Teng, Recent progress in design and preparation of glucose-responsive insulin delivery systems, J. Controlled Release, 321 (2020) 236-258.

[147] T. Thambi, J.H. Park, D.S. Lee, Stimuli-responsive polymersomes for cancer therapy, Biomater. Sci., 4 (2016) 55-69. 
[148] R. Chang, M. Li, S. Ge, J. Yang, Q. Sun, L. Xiong, Glucose-responsive biopolymer nanoparticles prepared by co-assembly of concanavalin A and amylopectin for insulin delivery, Ind. Crops Prod., 112 (2018) 98-104.

[149] M. Oroval, P. Díez, E. Aznar, C. Coll, M.D. Marcos, F. Sancenón, R. Villalonga, R. Martínez-Máñez, Self-Regulated Glucose-Sensitive Neoglycoenzyme-Capped Mesoporous Silica Nanoparticles for Insulin Delivery, Chemistry, 23 (2017) 1353-1360.

[150] I.-H. Cho, M.K. Shim, B. Jung, E.H. Jang, M.-J. Park, H.C. Kang, J.-H. Kim, Heat shock responsive drug delivery system based on mesoporous silica nanoparticles coated with temperature sensitive gatekeeper, Microporous Mesoporous Mater., 253 (2017) 96-101.

[151] J.-H. Park, Y.-H. Lee, S.-G. Oh, Preparation of Thermosensitive PNIPAm-Grafted Mesoporous Silica Particles, Macromol. Chem. Phys., 208 (2007) 2419-2427.

[152] Y. Su, O.F. Ojo, I.K.M. Tsengam, J. He, G.L. McPherson, V.T. John, J.A. Valla, Thermoresponsive Coatings on Hollow Particles with Mesoporous Shells Serve as StimuliResponsive Gates to Species Encapsulation and Release, Langmuir, 34 (2018) 14608-14616.

[153] M. Curcio, U. Gianfranco Spizzirri, F. Iemma, F. Puoci, G. Cirillo, O.I. Parisi, N. Picci, Grafted thermo-responsive gelatin microspheres as delivery systems in triggered drug release, Eur. J. Pharm. Biopharm., 76 (2010) 48-55.

[154] J. Shi, X. Liu, X. Sun, S. Cao, Hybrid alginate beads with thermal-responsive gates for smart drug delivery, Polym. Adv. Technol., 22 (2011) 1539-1546.

[155] L. Zhang, Y. Li, Z. Jin, J.C. Yu, K.M. Chan, An NIR-triggered and thermally responsive drug delivery platform through DNA/copper sulfide gates, Nanoscale, 7 (2015) 12614-12624.

[156] J. Wang, J. Zhao, Y. Li, M. Yang, Y.-Q. Chang, J.-P. Zhang, Z. Sun, Y. Wang, Enhanced Light Absorption in Porous Particles for Ultra-NIR-Sensitive Biomaterials, ACS Macro Lett., 4 (2015) 392-397.

[157] C. Park, K. Lee, C. Kim, Photoresponsive Cyclodextrin-Covered Nanocontainers and Their Sol-Gel Transition Induced by Molecular Recognition, Angew. Chem. Int. Ed., 48 (2009) 12751278.

[158] Y. Gao, M.-W. Chang, Z. Ahmad, J.-S. Li, Magnetic-responsive microparticles with customized porosity for drug delivery, RSC Adv., 6 (2016) 88157-88167.

[159] E. Ruiz-Hernández, A. Baeza, M. Vallet-Regí, Smart Drug Delivery through DNA/Magnetic Nanoparticle Gates, ACS Nano, 5 (2011) 1259-1266.

[160] J.L. Paris, P. de la Torre, M. Victoria Cabañas, M. Manzano, M. Grau, A.I. Flores, M. ValletRegí, Vectorization of ultrasound-responsive nanoparticles in placental mesenchymal stem cells for cancer therapy, Nanoscale, 9 (2017) 5528-5537.

[161] M. Gisbert-Garzaran, D. Lozano, M. Vallet-Regí, M. Manzano, Self-immolative polymers as novel pH-responsive gate keepers for drug delivery, RSC Adv., 7 (2017) 132-136.

[162] J. Wu, M.J. Sailor, Chitosan Hydrogel-Capped Porous SiO2 as a pH Responsive Nano-Valve for Triggered Release of Insulin, Adv. Funct. Mater., 19 (2009) 733-741.

[163] F. Chai, L. Sun, X. He, J. Li, Y. Liu, F. Xiong, L. Ge, T.J. Webster, C. Zheng, Doxorubicinloaded poly (lactic-co-glycolic acid) nanoparticles coated with chitosan/alginate by layer by layer technology for antitumor applications, Int. J. Nanomed., 12 (2017) 1791-1802.

[164] X. Li, C. Xie, H. Xia, Z. Wang, pH and Ultrasound Dual-Responsive Polydopamine-Coated Mesoporous Silica Nanoparticles for Controlled Drug Delivery, Langmuir, 34 (2018) 9974-9981. [165] S.-F. Lee, X.-M. Zhu, Y.-X.J. Wang, S.-H. Xuan, Q. You, W.-H. Chan, C.-H. Wong, F. Wang, J.C. Yu, C.H.K. Cheng, K.C.-F. Leung, Ultrasound, pH, and Magnetically Responsive 
Crown-Ether-Coated Core/Shell Nanoparticles as Drug Encapsulation and Release Systems, ACS Appl. Mater. Interfaces, 5 (2013) 1566-1574.

[166] X. Chen, H. Sun, J. Hu, X. Han, H. Liu, Y. Hu, Transferrin gated mesoporous silica nanoparticles for redox-responsive and targeted drug delivery, Colloids Surf., B, 152 (2017) 7784.

[167] Y. Yang, Y. Lin, D. Di, X. Zhang, D. Wang, Q. Zhao, S. Wang, Gold nanoparticle-gated mesoporous silica as redox-triggered drug delivery for chemo-photothermal synergistic therapy, J. Colloid Interface Sci., 508 (2017) 323-331.

[168] L. Sha, Q. Zhao, D. Wang, X. Li, X. Wang, X. Guan, S. Wang, "Gate” engineered mesoporous silica nanoparticles for a double inhibition of drug efflux and particle exocytosis to enhance antitumor activity, J. Colloid Interface Sci., 535 (2019) 380-391.

[169] Q. Zhang, J. Guo, X. Zhang, Y. Zhao, L. Cao, L. Sun, Redox- and enzyme-responsive fluorescent porous silica nanocarriers for drug delivery, Sens. Actuators, B, 276 (2018) 370-377. [170] L. Mondragón, N. Mas, V. Ferragud, C. de la Torre, A. Agostini, R. Martínez-Máñez, F. Sancenón, P. Amorós, E. Pérez-Payá, M. Orzáez, Enzyme-Responsive Intracellular-Controlled Release Using Silica Mesoporous Nanoparticles Capped with $\varepsilon$-Poly-L-lysine, Chem. Eur. J., 20 (2014) 5271-5281.

[171] A. Bernardos, L. Mondragón, E. Aznar, M.D. Marcos, R. Martínez-Máñez, F. Sancenón, J. Soto, J.M. Barat, E. Pérez-Payá, C. Guillem, P. Amorós, Enzyme-Responsive Intracellular Controlled Release Using Nanometric Silica Mesoporous Supports Capped with "Saccharides", ACS Nano, 4 (2010) 6353-6368.

[172] J.-Z. Wu, G.R. Williams, H.-Y. Li, D.-X. Wang, S.-D. Li, L.-M. Zhu, Insulin-loaded PLGA microspheres for glucose-responsive release, Drug Delivery, 24 (2017) 1513-1525.

[173] W. Zhao, H. Zhang, Q. He, Y. Li, J. Gu, L. Li, H. Li, J. Shi, A glucose-responsive controlled release of insulin system based on enzyme multilayers-coated mesoporous silica particles, Chem. Commun., 47 (2011) 9459-9461.

[174] Y. Zhao, B.G. Trewyn, I.I. Slowing, V.S.Y. Lin, Mesoporous Silica Nanoparticle-Based Double Drug Delivery System for Glucose-Responsive Controlled Release of Insulin and Cyclic AMP, J. Am. Chem. Soc., 131 (2009) 8398-8400.

[175] W. Gao, Y. Hu, L. Xu, M. Liu, H. Wu, B. He, Dual pH and glucose sensitive gel gated mesoporous silica nanoparticles for drug delivery, Chin. Chem. Lett., 29 (2018) 1795-1798.

[176] E.Y. Chen, W.F. Liu, L. Megido, P. Díez, M. Fuentes, C. Fager, E. Olsson, I. Gessner, S. Mathur, Chapter 3 - Understanding and utilizing the biomolecule/nanosystems interface, in: V. Uskoković, D.P. Uskoković (Eds.) Nanotechnologies in Preventive and Regenerative Medicine, Elsevier2018, pp. 207-297.

[177] T. Asefa, Z. Tao, Biocompatibility of Mesoporous Silica Nanoparticles, Chem. Res. Toxicol, 25 (2012) 2265-2284.

[178] L. Wu, M. Wu, Y. Zeng, D. Zhang, A. Zheng, X. Liu, J. Liu, Multifunctional PEG modified DOX loaded mesoporous silica nanoparticle@ $\mathrm{CuS}$ nanohybrids as photo-thermal agent and thermal-triggered drug release vehicle for hepatocellular carcinoma treatment, Nanotechnology, 26 (2014) 025102.

[179] R. Mo, Z. Gu, Tumor microenvironment and intracellular signal-activated nanomaterials for anticancer drug delivery, Mater. Today, 19 (2016) 274-283.

[180] J. Zhang, X. Jiang, X. Wen, Q. Xu, H. Zeng, Y. Zhao, M. Liu, Z. Wang, X. Hu, Y. Wang, Bio-responsive smart polymers and biomedical applications, J. Phys. Mater., 2 (2019) 032004. 
[181] W. Cheng, L. Gu, W. Ren, Y. Liu, Stimuli-responsive polymers for anti-cancer drug delivery, Mater. Sci. Eng. C, 45 (2014) 600-608.

[182] W. Lei, C. Sun, T. Jiang, Y. Gao, Y. Yang, Q. Zhao, S. Wang, Polydopamine-coated mesoporous silica nanoparticles for multi-responsive drug delivery and combined chemophotothermal therapy, Mater. Sci. Eng. C, 105 (2019) 110103.

[183] J. Lu, B. Luo, Z. Chen, Y. Yuan, Y. Kuang, L. Wan, L. Yao, X. Chen, B. Jiang, J. Liu, C. $\mathrm{Li}$, Host-guest fabrication of dual-responsive hyaluronic acid/mesoporous silica nanoparticle based drug delivery system for targeted cancer therapy, Int. J. Biol. Macromol., 146 (2020) 363373.

[184] S.H. van Rijt, T. Bein, S. Meiners, Medical nanoparticles for next generation drug delivery to the lungs, Eur. Respir. J., 44 (2014) 765-774.

[185] H.M. Abdelaziz, M. Gaber, M.M. Abd-Elwakil, M.T. Mabrouk, M.M. Elgohary, N.M. Kamel, D.M. Kabary, M.S. Freag, M.W. Samaha, S.M. Mortada, K.A. Elkhodairy, J.-Y. Fang, A.O. Elzoghby, Inhalable particulate drug delivery systems for lung cancer therapy: Nanoparticles, microparticles, nanocomposites and nanoaggregates, J. Controlled Release, 269 (2018) 374-392.

[186] F. Emami, S.J. Mostafavi Yazdi, D.H. Na, Poly(lactic acid)/poly(lactic-co-glycolic acid) particulate carriers for pulmonary drug delivery, J. Pharm. Invest., 49 (2019) 427-442.

[187] I. Kim, H.J. Byeon, T.H. Kim, E.S. Lee, K.T. Oh, B.S. Shin, K.C. Lee, Y.S. Youn, Doxorubicin-loaded porous PLGA microparticles with surface attached TRAIL for the inhalation treatment of metastatic lung cancer, Biomaterials, 34 (2013) 6444-6453.

[188] M. Qu, X. Jiang, X. Zhou, C. Wang, Q. Wu, L. Ren, J. Zhu, S. Zhu, P. Tebon, W. Sun, A. Khademhosseini, Stimuli-Responsive Delivery of Growth Factors for Tissue Engineering, Adv. Healthcare Mater., 9 (2020) 1901714.

[189] P. Lavrador, V.M. Gaspar, J.F. Mano, Stimuli-responsive nanocarriers for delivery of bone therapeutics - Barriers and progresses, J. Controlled Release, 273 (2018) 51-67.

[190] A. Santoveña, C. Monzón, C. Alvarez-Lorenzo, C. del Rosario, A. Delgado, C. Evora, A. Concheiro, M. Llabrés, J.B. Fariña, Structure-Performance Relationships of TemperatureResponsive PLGA-PEG-PLGA Gels for Sustained Release of Bone Morphogenetic Protein-2, J. Pharm. Sci., 106 (2017) 3353-3362.

[191] H. Qi, L. Yang, X. Li, X. Sun, J. Zhao, X. Hou, Z. Li, X. Yuan, Z. Cui, X. Yang, Systemic administration of enzyme-responsive growth factor nanocapsules for promoting bone repair, Biomater. Sci., 7 (2019) 1675-1685.

[192] Q. Gan, J. Zhu, Y. Yuan, H. Liu, J. Qian, Y. Li, C. Liu, A dual-delivery system of pHresponsive chitosan-functionalized mesoporous silica nanoparticles bearing BMP-2 and dexamethasone for enhanced bone regeneration, J. Mater. Chem. B, 3 (2015) 2056-2066. 